\title{
Social Media Data in an Augmented Reality System for Situation Awareness Support in Emergency Control Rooms
}

\author{
Jennifer Fromm ${ }^{1} \cdot$ Kaan Eyilmez $^{1} \cdot$ Melina Baßfeld $^{1} \cdot$ Tim A. Majchrzak $^{2} \cdot$ Stefan Stieglitz $^{1}$ \\ Accepted: 25 December 2020 / Published online: 6 January 2021 \\ (C) The Author(s) 2021
}

\begin{abstract}
During crisis situations, emergency operators require fast information access to achieve situation awareness and make the best possible decisions. Augmented reality could be used to visualize the wealth of user-generated content available on social media and enable context-adaptive functions for emergency operators. Although emergency operators agree that social media analytics will be important for their future work, it poses a challenge to filter and visualize large amounts of social media data. We conducted a goal-directed task analysis to identify the situation awareness requirements of emergency operators. By collecting tweets during two storms in Germany we evaluated the usefulness of Twitter data for achieving situation awareness and conducted interviews with emergency operators to derive filter strategies for social media data. We synthesized the results by discussing how the unique interface of augmented reality can be used to integrate social media data into emergency control rooms for situation awareness support.
\end{abstract}

Keywords Situation awareness · Emergency management $\cdot$ Emergency control rooms $\cdot$ Augmented reality $\cdot$ Social media analytics

\section{Introduction}

Crisis situations involve a high degree of uncertainty and the need for rapid, critical and potentially irreversible decisions (Rosenthal and Hart 1991). Emergency control rooms are facilities used during crisis situations to coordinate response and recovery actions, conduct strategic decision-making and manage resource allocation (Mignone and Davidson 2003). Among other sources, emergency operators obtain information through the calls they receive from citizens and decide about the resources required to support first responders at the scene (Militello et al. 2007). To make the best possible decisions about the allocation of resources, it is crucial for emergency operators to achieve a high level of situation awareness (Endsley and Garland 2000). This means they need to process sufficient information to develop an understanding of the present situation and project the future state of the situation (Endsley 1996). Especially in the beginning of a crisis

Tim A. Majchrzak

timam@uia.no

1 University of Duisburg-Essen, Duisburg, Germany

2 University of Agder, Kristiansand, Norway situation, there is often a lack of information and emergency operators wish for access to further credible data sources (Tapia et al. 2013).

The adoption of smartphones equipped with multiple sensors and a constant Internet connection has increased the creation of incident reports in crisis situations and the volume of available information. In particular, social media posts from eyewitnesses are seen as a potentially valuable data source for emergency operators (Palen and Vieweg 2008; Palen et al. 2009; Sutton et al. 2008). Still, control rooms are hesitating to make use of social media analytics as it is challenging to filter relevant and credible information (Landwehr and Carley 2014). Moreover, social media data are complex since they are generated in an informal way, include many different data formats (such as text, video, audio) and are generated by unknown and diverse users and organizations (Stieglitz et al. 2018b). Due to the large amount of data available on social media, control rooms need filtering algorithms to categorize the data and visualize them in a meaningful way (Ludwig et al. 2015a; Stieglitz et al. 2018e). In addition, the integration of social media data into the information systems currently used in control rooms poses a further challenge that needs to be addressed.

Information systems for emergency management must be designed to reduce the operator's workload and support the 
decision-making process in the dynamic work environment (Buck et al. 2006; Carver and Turoff 2007; Taylor 2004). The following quote illustrates the importance of information systems in this work environment: "A crisis management plan is only as good as the information system that supports it" (Housel et al. 2006). Over the years, the used systems have improved significantly through the lessons learned from retrospective analyses of real-world disasters (Perry 2003). However, crisis situations are also changing as they are not only becoming more complex in nature (Rosenthal et al. 2001) but their number is also "increasing in proportion to the growing complexity of the world" (Feng and Lee 2010). Therefore, it is important to constantly improve the used information systems to keep up with these new developments. Augmented reality is a technology that made major progress in the last decade and is now implemented in the industry (Palmarini et al. 2018). Recent results revealed that this technology can help operators to work faster and reduce their mental workload, for example, in procedural work where a fixed sequence of activities are carried out to achieve a specific result which is common for installation, assembly, and maintenance work (Braly et al. 2019). This reduction can lead to an increased situation awareness and in turn to better decision-making (Endsley et al. 2003). It still needs to be investigated to what extent these findings also apply for the operators working in emergency control rooms.

The goal of our research is to propose a conceptual augmented reality design for improving the situation awareness of emergency operators. First, we used the technique of goaldirected task analysis to analyze the situation awareness requirements of emergency operators. Second, we collected Twitter data during two heavy storms in Germany to discuss the usefulness of different types of tweets with emergency operators. Based on the results, we derived filter strategies that allow to identify the tweets that are perceived as most useful by emergency operators in crisis situations. Third, we applied the eight design principles for situation awareness (Endsley et al. 2003) to propose a conceptual augmented reality design for integrating the filtered Twitter data into the information systems of control rooms. Hence, we answer the following research questions with our study:

RQ1: What are the situation awareness requirements for operators working in emergency control rooms?

RQ2: Which types of Twitter data do emergency operators perceive as useful for achieving situation awareness?

RQ3: How can augmented reality be used to visualize the types of Twitter data which are perceived as useful by emergency operators for achieving situation awareness?

The remainder of this article is structured as follows: In the next section, we provide the theoretical background on situation awareness. Subsequently, we summarize previous studies on social media analytics and augmented reality in emergency management. Then, we describe our two-step research approach consisting of a goal-directed task analysis and expert interviews. Afterwards, we present our findings and answer our research questions by discussing the identified situation awareness requirements, derived filter strategies, and conceptual augmented reality design for integrating Twitter data into control rooms and improving situation awareness of emergency operators. We conclude with a summary of our contribution, limitations, and suggestions for future research.

\subsection{Research Background}

\subsubsection{Situation Awareness}

The formal definition of situation awareness is "the perception of the elements in the environment within a volume of time and space, the comprehension of their meaning, and the projection of their status in the near future" (Endsley and Connors 2008). This awareness usually focuses on the information needed for a specific task or goal and is therefore critical for effective decision-making (Endsley et al. 2003). Typically, the concept of situation awareness is applied to operational tasks such as driving a car or flying a plane (Endsley and Garland 2000). Operators working in emergency control rooms require individual situation awareness, team situation awareness and shared situation awareness which emphasizes the need to achieve "a shared understanding of that subset of information that is necessary for each of their goals" (Endsley et al. 2003). Based on the formal definition, situation awareness comprises of three different levels: 1. Perception of the elements in the environment, 2. Comprehension of the current situation, and 3. Projection of the future status (Valecha 2019). The first step towards achieving situation awareness solely represents the receipt of information in its raw form and does not comprise any interpretation of the data (Stanton et al. 2001). The second step towards achieving situation awareness is to understand what the perceived data means in relation to the goal and objectives (Endsley et al. 2003). This comprehension is based on schemata or knowledge structures that are stored in the long-term memory and are activated by recognized patterns in the perceived elements (Sarter and Woods 1991). The third level of situation awareness describes the ability to predict how perceived elements in the environment will impact the future (Stanton et al. 2001). This allows operators to proactively avoid undesired situations and respond faster which is why a lot of experts in different work environments devote a significant amount of their time to form this ability (Endsley et al. 2003). In combination, the three levels of situation awareness help to make wellfounded decisions which will affect the current situation. 
The operator's decision-making performance will change the state of the environment, resulting in new elements the operator can perceive, comprehend, and use to predict future events. Figure 1 shows additional factors that have an impact on the achievement of situation awareness.

The operator's expertise helps to develop mental models and schemata allowing the comprehension and projection of the future faster and with less effort (Salvendy 2012). This can lead to a level of automation in mental processing that can create a positive effect on situation awareness since it reduces the mental workload of the operator (Endsley et al. 2003). Furthermore, the operator may have preconceptions of what he or she should see or hear in a particular situation because of prior experiences, mental models, and instructions (Endsley and Garland 2000). The capability and user interface of an information system also influence the achievement of situation awareness. The presented information and provided functionalities can be beneficial for obtaining situation awareness. However, especially with many elements presented simultaneously, it is important to support the perception of the most important elements (Endsley et al. 2003). Additionally, the goals of the operator are essential to the development of situation awareness as for many operators their individual goals determine the elements of the environment that are perceived (Endsley et al. 2003). This active approach of perceiving elements is also known as goal-driven information processing (Casson 1983). Conversely, data-driven processing of data describes when elements are perceived unintentionally and independent of the operator's goal (Endsley et al. 2003). Alternating between these two forms of processing is one of the most important mechanisms supporting situation awareness (Endsley et al. 2003). For instance, when an operator only focuses on a given goal and fails to consider cues that indicate that a new goal is more important, he or she might make bad decisions. At the same time, relying on data-driven processing is overly taxing and highly ineffective in an attempt to achieve a specific goal (Endsley and Garland 2000). Therefore, the right balance is essential for a good job performance. By understanding how an operator selects and uses goals, it is possible to design an information system that supports the perception of important elements in specific situations. Endsley et al. (2003) proposed eight design principles for creating interfaces that effectively support the achievement of situation awareness (Table 1).

\subsubsection{Social Media Analytics in Emergency Management}

The term social media describes "a group of Internet-based applications that build on the ideological and technological foundations of Web 2.0 and that allow the creation and exchange of user-generated content" (Kaplan and Haenlein 2010). Since everyone with a smartphone can share videos and pictures from the emergency scene, information can already be found on social media before authorities or

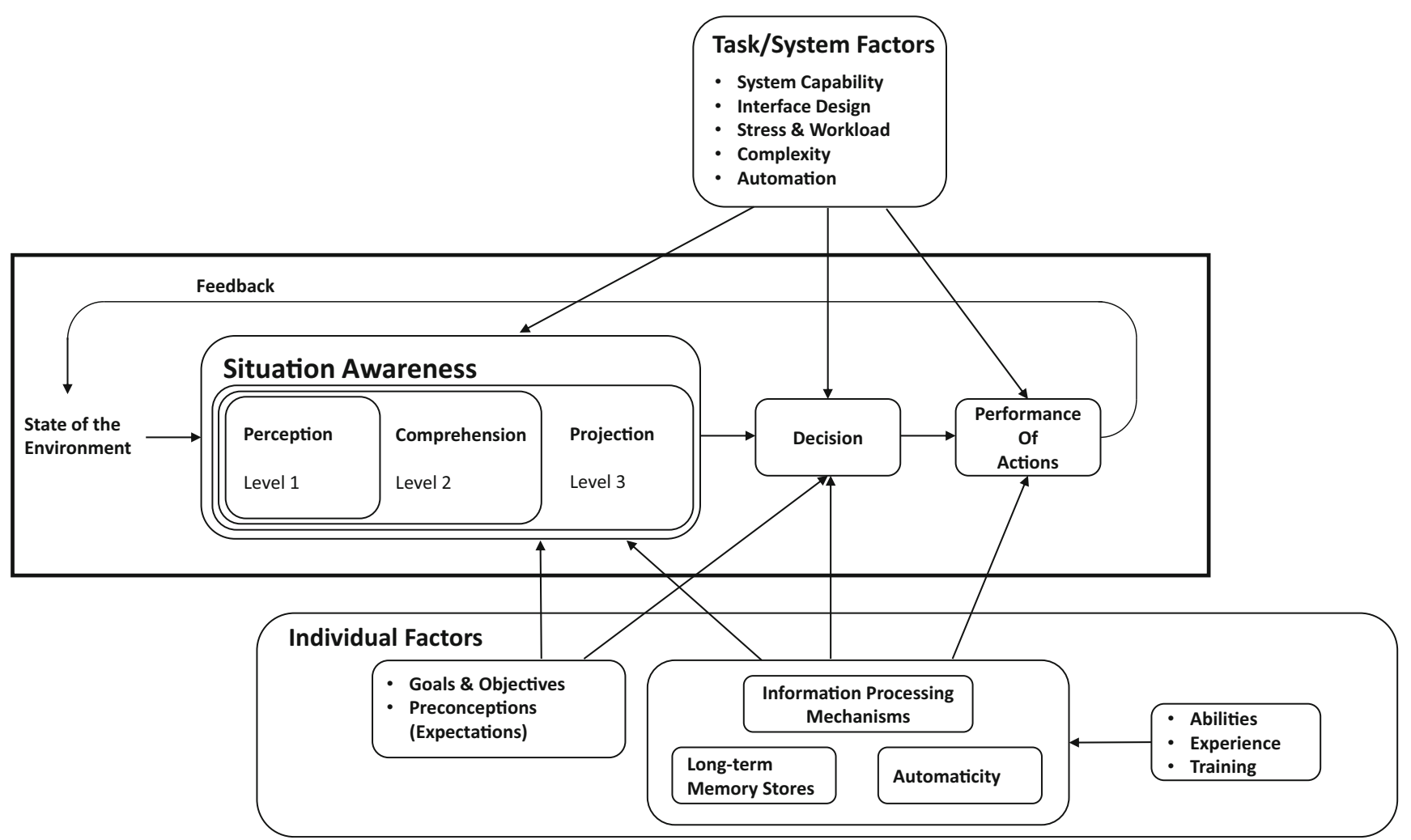

Fig. 1 Model of situation awareness in dynamic decision-making (adapted from Endsley et al. 2003) 
Table 1 Design principles for situation awareness (Endsley et al. 2003)

\begin{tabular}{|c|c|}
\hline Design principle & Description \\
\hline Organize information around goals & $\begin{array}{l}\text { All information that is necessary to make the major decisions related } \\
\text { to a specific goal should be organized in close vicinity. Thus, } \\
\text { information related to the same goal should e.g. not be spread } \\
\text { across multiple displays. }\end{array}$ \\
\hline $\begin{array}{l}\text { Present level } 2 \text { information directly - } \\
\text { support comprehension }\end{array}$ & $\begin{array}{l}\text { Due to working memory limitations, it facilitates the work of } \\
\text { operators to display level } 2 \text { information directly instead of level } 1 \\
\text { information. The trustworthiness of tweets, for example, could be } \\
\text { calculated by the system directly, so that operators do not have to } \\
\text { use cognitive resources to evaluate the trustworthiness by } \\
\text { themselves. }\end{array}$ \\
\hline $\begin{array}{l}\text { Provide assistance for level } 3 \text { situation } \\
\text { awareness projections }\end{array}$ & $\begin{array}{l}\text { As level three of situation awareness is hardest to achieve and } \\
\text { requires well-developed mental models, an information system } \\
\text { should support the projection of future states. For example, a trend } \\
\text { display showing changes of a parameter over time allows the } \\
\text { operator to predict future changes of this parameter. }\end{array}$ \\
\hline Support global situation awareness & $\begin{array}{l}\text { Information systems should provide a high-level overview of the } \\
\text { situation and operator goals to achieve global situation awareness. } \\
\text { Excessive menuing and windowing narrow the attention to a } \\
\text { subset of the relevant information and should be avoided. }\end{array}$ \\
\hline $\begin{array}{l}\text { Support tradeoffs between goal-driven } \\
\text { and data-driven processing }\end{array}$ & $\begin{array}{l}\text { Goal-driven and data-driven processing (principle } 1 \text { vs. } 4 \text { ) should } \\
\text { complement each other. Highly salient cues (e.g. flashing lights, } \\
\text { loud sounds) direct attention away from goal-driven processing } \\
\text { and should be reserved for the most critical events. }\end{array}$ \\
\hline $\begin{array}{l}\text { Make critical cues for schema activation } \\
\text { salient }\end{array}$ & $\begin{array}{l}\text { The activation of mental models and schemata are critical to achieve } \\
\text { the highest level of situation awareness. Therefore, it is essential } \\
\text { to identify cues that activate certain mental models or schemata } \\
\text { and make these salient in the interface design. }\end{array}$ \\
\hline Take advantage of parallel processing & $\begin{array}{l}\text { The amount of visual information that can be processed by operators } \\
\text { is limited. However, different modalities (e.g. visual, auditory, } \\
\text { and tactile information) draw on different cognitive resources. An } \\
\text { information system that supports these different modalities allows } \\
\text { operators to process more information at once. }\end{array}$ \\
\hline Use information filtering carefully & $\begin{array}{l}\text { Computer-driven filtering reduces information overload but at the } \\
\text { same time decreases global situation awareness because } \\
\text { individual differences in situation awareness formation are } \\
\text { neglected. Therefore, it is recommended to allow individual } \\
\text { operators to determine which information they need to look at. }\end{array}$ \\
\hline
\end{tabular}

traditional media publish their reports (Cameron et al. 2012; Crooks et al. 2013; Huang et al. 2015; Mirbabaie and Zapatka 2017; Stieglitz et al. 2018d), sometimes even before emergency responders are on site (Stieglitz et al. 2018a). The wealth of user-generated content on social media could therefore serve as an additional information source for emergency operators to achieve situation awareness. Previous research has highlighted the usefulness of social media analytics before, during, and after a disaster (Ahmed 2011; Ghosh et al. 2018, Houston et al. 2015; X. Li et al. 2019). This applies especially to the micro-blogging service Twitter, which allows users to communicate in real time by allowing them to post public messages of up to 280 characters including images, videos, and links. There are example cases displaying the responsiveness of Twitter, e.g. in the 2011 Christchurch Earthquake in New Zealand, where "the first tweet was within $30 \mathrm{~s}$, the first photo was within 4 min" (McLean 2015). Especially at the beginning of a crisis situation, emergency managers perceive a lack of reliable information (Tapia et al. 2013). Extracting posts from eyewitnesses could therefore provide actionable information for the planning of emergency operations (Landwehr and Carley 2014) and close information gaps concerning the situation at emergency scenes (Young et al. 2013) which accelerates the response time and reduces risks to citizens (Luna and Pennock 2018; Stieglitz et al. 2018c).

Although social media analytics could contribute to achieving situation awareness, emergency management organizations are still hesitant to adopt social media (Plotnick and Hiltz 2016; Stieglitz et al. 2018c). Nowadays, many emergency management organizations maintain a presence on social media to reach a larger percentage of the population in times of crisis (Eismann et al. 2016). However, analyzing social 
media data is still perceived rather as an experiment than as common practice (Imran et al. 2015; Lazreg et al. 2018; McLean 2015). Previous research identified the questionable veracity of social media information, the large volume of available data, the variety of data formats, and the high velocity of information diffusion as the most important technological challenges inhibiting the adoption of social media analytics in crisis management (Stieglitz et al. 2018c). Despite these challenges, many emergency managers acknowledge the potential benefits of social media data and believe that social media analytics will become an important part of their work routine in the future (Reuter et al. 2015). Regarding the questionable veracity of information, addressing the credibility of social media information is still seen as one main priority for the future development of social media analytics (Hiltz et al. 2020). Due to the unpredictable nature of crisis situations, emergency managers are used to limited and vague information, and therefore could trust social media sources, especially in the beginning of a crisis (Palen et al. 2011). However, it still poses a challenge to filter potentially useful information from the large number of irrelevant social media posts (McLean 2015). To address these challenges, Ludwig et al. (2015a) emphasize the need for filtering algorithms allowing to separate useful and credible information from the wealth of irrelevant social media content in a timely manner.

In previous research, crowdsourcing and automated approaches based on machine learning were identified as promising concepts (Imran et al. 2013; Tapia et al. 2013). Although crowdsourcing approaches can benefit emergency operations, they reach their limit as soon as the humans fueling them reach theirs. Therefore, automated approaches might be appropriate to solve the problem of analyzing the high number of social media posts in addition to crowdsourcing approaches (Hiltz and Plotnick 2013). However, it is difficult to correctly classify tweets using machine learning approaches because of the short text format (C. Li et al. 2012). Despite the advances that were made, it has been argued that the proposed solutions must become more accurate (Tapia et al. 2013). The examples in Table 2 demonstrate that the development of social media analytics applications for emergency management is already advanced and offering a variety of approaches with different strengths, while all of them express a demand for improvement and more accuracy. Especially, the processing time can be very long, because of the volume of data and the need of human input for labels (Troudi et al. 2018) and some authors argue that natural language processing needs to be improved (Aupetit and Imran 2017; Luchetti et al. 2017). Also, the automatic classifications could be more detailed and more robust, which implies the need for more detailed test labels (Alam et al. 2020; X. Li et al. 2019). Moreover, Lazreg et al. (2018) argue that social media analytics has to focus on providing information answering the specific needs of individual emergency managers.

\subsubsection{Augmented Reality in Emergency Management}

Recently, augmented reality has received attention in information systems research as the technology allows to present information in direct association with relevant elements in the physical world (Olshannikova et al. 2015). The unique interface of augmented reality is considered most useful when "the success [of a task] is increased or made more likely (...) through additional visual information being presented alongside the physical world" (Steffen et al. 2017). According to prior studies, the unique way of presenting information can improve the user's analytical reasoning and decision-making abilities (Chandler et al. 2015; ElSayed et al. 2016). Augmented reality systems are characterized through a combination of real and virtual content (Azuma 1997). This distinguishes them from virtual reality systems, which allow the user to immerse completely in a virtual world (Milgram and Kishino 1994). In the context of our study, we focus on the potential of augmented reality as it is critical for emergency operators to continuously perceive their real environment while processing information. This is due to the fact that, similar to the emergency response forces in the field, it is essential for operators in emergency control rooms to cooperate and achieve shared situational awareness for a successful emergency management (Seppänen et al. 2013). Augmented reality experiences are realized on different devices such as head-up displays, head-mounted displays, virtual retina displays, smart glasses, and hand-held devices (Van Krevelen and Poelman 2010). In previous studies, participants reported the heavy weight and the limited field of view as the major disadvantages of wearable devices (Braly et al. 2019). Moreover, the usage of augmented reality can lead to attention tunneling because the user's attention is drawn to highlighted objects (Dixon et al. 2013).

Nevertheless, there are already examples of augmented reality applications that have been used to support the development of situation awareness. For example, augmented reality systems have improved situation awareness when driving a vehicle (Park et al. 2015), riding a motorcycle (Jenkins and Young 2016), and driving automated cars (Lindemann et al. 2019). Similar results were also found in a study investigating the effects of wearable augmented reality on the operators of safety-critical systems. By providing real-time information through augmented reality, an improvement of the operator performance and situation awareness could be ascertained. These impacts are important because in a security-critical environment such as emergency management, they can prevent catastrophic loss of life or damage to property or the environment (Rowen et al. 2019). Additionally, Berkemeier et al. (2019) identified cross-industrial application areas and use cases for augmented reality systems based on the unique features of this technology. These identified application areas include communication, data visualization, text handling, 
Table 2 Overview about state-of-the-art approaches for filtering social media data

\begin{tabular}{|c|c|c|c|}
\hline Reference & Approach & Filter Criteria & Description \\
\hline $\begin{array}{l}\text { Ludwig et al. } \\
\qquad(2015 b)\end{array}$ & $\begin{array}{l}\text { automated, } \\
\text { crowdsourcing }\end{array}$ & $\begin{array}{l}\text { search keywords, time period, retweets and } \\
\text { up-to-datedness, mobile app requests }\end{array}$ & $\begin{array}{l}\text { CrowdMonitor: Captures real movements via a mobile app } \\
\text { and digital activities on social media to support situation } \\
\text { awareness, crisis communication and integration of citizen } \\
\text { volunteers in emergency management. }\end{array}$ \\
\hline McLean (2015) & automated & eyewitness reports & $\begin{array}{l}\text { Algorithm that could find } 40 \text { to } 80 \% \text { of eyewitness reports in } \\
\text { a database, while being } 80 \text { to } 90 \% \text { accurate. }\end{array}$ \\
\hline Basu et al. (2016) & $\begin{array}{l}\text { automated, } \\
\text { crowdsourcing }\end{array}$ & $\begin{array}{l}\text { directly and actively asking for relevant } \\
\text { information }\end{array}$ & $\begin{array}{l}\text { Eyewitness reports are collected by asking the crowd about } \\
\text { the disaster scene and automatically summarized to } \\
\text { support situation awareness and decision making. }\end{array}$ \\
\hline $\begin{array}{l}\text { Luchetti et al. } \\
\text { (2017) }\end{array}$ & automated & $\begin{array}{l}\text { search keywords and hashtags, activity } \\
\text { period, geographic boundaries }\end{array}$ & $\begin{array}{l}\text { Whistland: An augmented reality solution consisting of a } \\
\text { mobile app and an analytics dashboard that has multiple } \\
\text { analysis views, tabular data and heatmaps. }\end{array}$ \\
\hline $\begin{array}{l}\text { Avvenuti et al. } \\
\quad(2018)\end{array}$ & automated & $\begin{array}{l}\text { word embeddings, semantic annotators, } \\
\text { collaborative knowledge-bases }\end{array}$ & $\begin{array}{l}\text { CrisMap: A crisis mapping system based on damage } \\
\text { detection and geoparsing, visualized in customizable, } \\
\text { web-based dashboards. Capable of quickly analyzing tex- } \\
\text { tual social media data and producing crisis maps. }\end{array}$ \\
\hline $\begin{array}{l}\text { Bossu et al. } \\
\quad(2018)\end{array}$ & crowdsourcing & $\begin{array}{l}\text { asking for reports on the severity of an } \\
\text { earthquake }\end{array}$ & $\begin{array}{l}\text { LastQuake: Intended for earthquakes can process information } \\
\text { from websites, a Twitter quakebot, and a smartphone app. }\end{array}$ \\
\hline $\begin{array}{l}\text { Troudi et al. } \\
\text { (2018) }\end{array}$ & automated & basic dimensions (topic, time, location) & $\begin{array}{l}\text { Collects big data from various social media platforms as a } \\
\text { mashup to detect disaster events. }\end{array}$ \\
\hline $\begin{array}{l}\text { X. Li et al. } \\
\text { (2019) }\end{array}$ & automated & depictions of disaster damage & $\begin{array}{l}\text { Identifying disaster images by differentiating between } \\
\text { damage and no-damage depictions. }\end{array}$ \\
\hline $\begin{array}{l}\text { Zahra et al. } \\
\qquad(2020)\end{array}$ & $\begin{array}{l}\text { automated, } \\
\text { crowdsourcing }\end{array}$ & $\begin{array}{l}\text { domain-expert features combined with textual } \\
\text { features }\end{array}$ & $\begin{array}{l}\text { Identifying and classifying eyewitness messages in direct, } \\
\text { indirect and vulnerable eyewitnesses using signal } \\
\text { expressions. }\end{array}$ \\
\hline
\end{tabular}

and navigation which are also relevant for the work in emergency control rooms. Augmented reality could be beneficial in these areas by processing data to enable context-adaptive functions and information to enhance the operator's workflow (Berkemeier et al. 2019). Further examples of augmented reality use in the field of emergency management can be found in the literature: For instance, the multi-agent system called Smart Augmented Field of Emergency combines augmented reality, wearable computing, and intelligent agents to support teams in emergency and rescue scenarios (Brunetti et al. 2015). Furthermore, the augmented reality application THEMIS-AR was developed to assist first responders in disaster relief operations (Nunes et al. 2019). The application was designed to gather information, offer advice and guidance on response priorities, and provide situation awareness information based on georeferenced pictures that could be shared among different users. In addition, Brandao and Pinho (2017) made suggestions on how augmented reality could be used to improve the situation awareness of dismounted operators who tend to deal with a large amount of volatile information. Luchetti et al. (2017) describe the advantages of applying augmented reality on the emergency scene with their tool Whistland as "making the information from social and sensor networks accessible for quick interpretation of geo-data to professionals and common users working on the scene of an emergency". Hereby, Luchetti et al. (2017) highlight the capability of augmented reality to simplify visualization and improve situation awareness. In the case of Whistland, the focus lies on mobile applications for the emergency field operators. In summary, most studies so far focused on augmented reality to improve situation awareness in other contexts than emergency management or on supporting emergency response teams in the field. However, it still constitutes a research gap to examine how augmented reality can be used to increase situation awareness and decision-making in the control room work environment.

\subsection{Research Approach}

\subsubsection{Expert Interviews and Goal-Directed Task Analysis}

The goal-directed task analysis is a cognitive task analysis technique that allows to identify critical decisions and information requirements of operators in various application domains (Endsley 1993). This method focuses on the basic goals of the operator, major decisions that need to be made to accomplish these goals and the situation awareness requirements that are mandatory for decision-making (D. G. Jones et al. 2012). This method is suitable for exploring what operators ideally want to know, regardless of whether this information is 
already available (Endsley et al. 2003). The knowledge of the required information helps designers to find better ways for the presentation of situation awareness information which leads to an improved decision-making performance of operators (Paulusová and Paulus 2018). To obtain this knowledge, interviews should be conducted with subject matter experts who have extensive knowledge of the operator's job (Rummukainen et al. 2015). The results are organized into hierarchical charts depicting the overall operator goal, the major goals, the sub goals, the decisions that need to be made for each sub goal, and the situation awareness requirements for each decision (Usher and Kaber 2000). The hierarchical chart aids in identifying the essential information that has to be provided by an information system to support the operator's situation awareness.

Goals are higher-order objectives necessary for a successful job performance and have to be distinguished from tasks or information requirements. Every major goal and subgoal is numbered to define the branch in which it is located; however, the numbers do neither indicate the sequence nor priority of goals. In some cases, a sub goal may be relevant for more than one major goal. In these cases, the sub goal can be described in depth at one part of the hierarchical chart and referenced at another part of the hierarchical chart using callouts. Each major goal forms an individual branch in the hierarchical chart with its own sub goals, decisions and situation requirements. Decisions are presented as octagons and phrased as questions that have to be answered. The subsequent level in the individual major goal branch includes the situation awareness requirements which are presented as rectangles and describe the information needed to answer the questions. The situation awareness requirements can be listed in an intended stacked format according to the level of situation awareness they belong to. This ensures that all situation awareness levels are considered when designing an information system for the operator's goals.

As part of the goal-directed task analysis, we conducted expert interviews with nine emergency operators working at fire departments throughout Germany (see Table 3), as these are the main responsible institutions in disaster control and civil protection activities (BBK 2020). The interviewees were selected due to their job experience to ensure that they were familiar with the goals, decisions, and situation awareness requirements in the control room work environment. Additionally, we selected operators with different roles in the operation center to consider different perspectives, and thus improve the depth of information obtained.

At the beginning, the participants were informed about the goal of the interview and their rights as participants. The interviewees gave their written consent to the recording of the interviews. In the first part of the interview, we asked the participants to introduce themselves and to talk about their tasks, job experience and position at the emergency operation
Table 3 Overview of respondents: first round of interviews

\begin{tabular}{llll}
\hline No. & Gender & Job Title & Experience \\
\hline P01 & male & Control Room Group Manager & 16 years \\
P02 & male & Control Room Group Manager & 3 years \\
P03 & male & Dispatcher & 9 years \\
P04 & male & Situation Service Leader & 12 years \\
P05 & male & Control Room Shift Supervisor & 22 years \\
P06 & male & Dispatcher & 17 years \\
P07 & female & Dispatcher & 1 year \\
P08 & male & Operations Manager & 15 years \\
P09 & male & Operations Manager & 7 years \\
\hline
\end{tabular}

center. We then explained the goal-directed task analysis technique to the interviewees and presented them a template for creating the primary goal hierarchy. In the second part of the interview, we asked the operators about the relevant goals to achieve a successful job performance and to describe their working steps in a typical emergency case chronologically. Afterwards, we presented a template for describing a major goal in detail to the participants. In the third part of the interview, we aimed to identify the decisions and situation awareness requirements related to the mentioned goals by repeatedly asking the following questions suggested by Endsley et al. (2003): What decisions do you have to make to achieve this goal? What do you need to know to make that decision? Which information are needed to make that decision? How do you use that information? What would you ideally like to know? How do people do this badly? What do they typically fail to consider? An overview about the structure and main questions asked in the expert interviews can be found in Table 4.

After each interview, we created a transcript following the rules of Kuckartz et al. (2008) and used the provided information to create a preliminary version of the hierarchical chart. We subsequently discussed this chart with the interviewees. This way, they could add, remove or edit certain aspects of the hierarchical chart and therefore improve the results. This procedure is also recommended by (Endsley et al. 2003) since it allows a review of the goals, decisions and situation awareness requirements by another person who is familiar with the illustrated steps. We conducted interviews until we reached theoretical saturation, meaning that the last interview did not result in any changes to the hierarchical chart. In the last part of the interview, we asked the participants how satisfied they were with the information systems currently used in control rooms, how well these meet the needs of the operators, and how these could be improved. Overall, the conducted interviews took between $30 \mathrm{~min}$ and one hour. 
Table 4 Structure and main questions of the first round of expert interviews

\begin{tabular}{|c|c|}
\hline Part & Main questions \\
\hline Introduction & $\begin{array}{l}\text { Sociodemographic data (age, job title, professional experience, } \\
\text { personal tasks) } \\
\text { Information about the emergency control room (responsibilities, } \\
\text { tasks, structure, equipment, types of crisis situations) }\end{array}$ \\
\hline Major Goals, Sub Goals, and Work Steps & $\begin{array}{l}\text { Description of work steps during a typical emergency } \\
\text { - What are the first questions you ask in an emergency call? } \\
\text { - How do you process the information received during an } \\
\text { emergency call? } \\
\text { - How do you inform the first responders? } \\
\text { - How and when do you inform other authorities that are needed at } \\
\text { the emergency location? } \\
\text { - Identification of major goals and sub goals } \\
\text { - What are the goals of an emergency operator? } \\
\text { - When you look at the goal hierarchy template, which of these } \\
\text { goals would you classify as major goals and sub goals? }\end{array}$ \\
\hline $\begin{array}{l}\text { Decisions and Situation Awareness } \\
\text { Requirements for Each Major Goal }\end{array}$ & $\begin{array}{l}\text { The questions suggested by Endsley et al. (2003) were repeated } \\
\text { for each major goal: } \\
\text { - What decisions to you have to make to achieve this goal? } \\
\text { - What do you need to know to make that decision? } \\
\text { - Which information are needed to make that decision? } \\
\text { - How do you use that information? } \\
\text { - What would you ideally like to know? } \\
\text { - How do people do this badly? } \\
\text { What do they typically fail to consider? }\end{array}$ \\
\hline
\end{tabular}

\subsection{Twitter Data Analysis and Expert Interviews}

To examine which situation awareness requirements could be fulfilled by integrating social media data into the information systems of control rooms, we first collected tweets during the storms Dragi and Eberhard in Germany and then conducted a second round of interviews with emergency operators about the usefulness of the collected data. Storm front Dragi was a less severe event on 09 March 2019 followed by the main storm front Eberhard that crossed the middle of Germany from west to east on 10 March 2019. In combination, these storm fronts resulted in the second highest warning level for storms in Germany and caused 10,000 operations for the fire department in the federal state of North Rhine-Westphalia (Waz 2019). The news reported on several property damages and impacted victims of the storm, namely 27 injured and one dead person in North Rhine-Westphalia. We collected the storm-related tweets on 10 March 2019 using a selfprogrammed java tool connected to the Twitter Search API. The search terms were German equivalents for the keywords "storm", "storm front" and "extreme weather", from which a tweet had to contain at least one to be included in the dataset. We decided against using the names of the storms as keywords, because they have an ambiguous meaning in
German, and therefore many irrelevant tweets would have been collected. In total, the data set contained 13,155 tweets of which 6843 were retweets. The goal of the subsequent analysis was to identify the tweets from different category types that were rated most relevant by users and select these as examples for the interviews with the emergency operators. In a first step, we excluded all retweets, replies, and comments since these include duplicate information or are difficult to interpret without reading the related original tweet. By removing these types of postings, the data set was reduced to 6312 original tweets. In a second step, we excluded all original tweets with less than ten retweets since previous research has suggested that the retweet count can be used as an indicator for relevancy (Starbird et al. 2012). Finally, the data set contained 172 original tweets representing $1.31 \%$ of the total data set and $2.72 \%$ of the original tweets.

The remaining 172 original tweets were manually categorized by data format, role of the communicator, and type of content. Regarding the data format, we distinguished between tweets that consisted of 1) text only, 2) text and image, 3) text and video / GIF-file, 4) text and URL, and 5) mixed data formats (e.g. text, image, and URL). For categorizing the communicator's role, we combined the classification schemes from Stieglitz et al. (2017) and Olteanu et al. (2015) who 
identified the following communication roles during crisis situations: media organizations (e.g. news organizations, weather channels), governmental organizations (e.g. local or national administration, political parties, and public authorities), juristic persons (e.g. business organizations, nongovernmental organizations), private persons (e.g. eyewitnesses, non-affected persons), and public persons (e.g. journalists, politicians, and celebrities). To categorize the type of content, we adopted the classification scheme from Heverin and Zach (2012) who distinguish between information, opinion, technology, emotion, and action tweets during crisis situations. Due to the large number of informative tweets in the dataset, we inductively generated subcategories for the category of information-related tweets (news, weather, traffic, and eyewitness reports). Once we completed the manual categorization, we selected the three most retweeted tweets for each category to present these to the interviewees as examples of realistic Twitter communication during a storm. An overview about the selected 21 example tweets can be found in Table 5 .

We then conducted semi-structured expert interviews with five emergency management officers working at fire departments throughout Germany (see Table 6). All interviewees had experience with the work in control rooms and were involved in the emergency response to a storm event. To consider different perspectives about the usefulness of social media data, we have selected interview partners working at institutions with various implementation levels of social media. While the fire department of one interviewee was not using social media at all, the remaining fire departments used Twitter and Facebook for crisis communication and implemented a manual screening of tweets into their work routine.

At the beginning, the respondents were asked to introduce themselves and describe the typical work processes in a control room during a crisis situation. The interviewees also described the information sources currently used in their work. Afterwards, we asked the interviewees to describe how the fire department responded to the storms Dragi and Eberhard to get an overview about the timeline from the view of an emergency agency. Then, we presented the representative sample of tweets from our Twitter dataset to the interviewees and asked them to rate the usefulness of these tweets providing them with a scale from 1 (not useful at all) to 5 (very useful). During the main part of the interviews, we asked the respondents to explain the reasons for their evaluation in detail. Thereby, we frequently used follow-up questions to obtain more detailed information about the usefulness of the different data formats, communicator's roles, and content types. We ended the interviews with questions about the interviewees' intention to use social media as part of their work in the future. An overview about the structure and main questions asked in the expert interviews can be found in Table 7 .
Table 5 Overview of the selected example tweets

\begin{tabular}{llll}
\hline Content category & Communicator's role & Data format & \# Retweets \\
\hline information & media organization (weather channel) & text and URL & 128 \\
(news) & media organization (news organization) & text and URL & 40 \\
& public person (journalist) & text and video/GIF-file & 29 \\
information & media organization (weather channel) & text and image & 141 \\
(weather) & media organization (weather channel) & text and image & 116 \\
& media organization (weather channel) & text and image & 90 \\
information & juristic person (business organization) & text only & 159 \\
(traffic) & media organization (news organization) & text only & 99 \\
& juristic person (business organization) & text and URL & 68 \\
information & public person (journalist) & text and image & 54 \\
(eyewitness report) & private person (eyewitness) & text and image & 45 \\
& private person (eyewitness) & text and video/GIF-file & 39 \\
opinion & public person (journalist) & text only & 36 \\
& public person (journalist) & text only & 23 \\
& public person (journalist) & text and image & 10 \\
emotion & governmental organization (political party) & text and image & 65 \\
& private person (eyewitness) & text only & 29 \\
& private person (eyewitness) & text only & 16 \\
action & private person (non-affected person) & text, image, and URL & 458 \\
& juristic person (registered association) & text and image & 56 \\
& media organization (news organization) & text only & 53 \\
\hline & & & \\
& & & \\
& & &
\end{tabular}


Table 6 Overview of respondents: second round of interviews

\begin{tabular}{|c|c|c|c|c|c|}
\hline \multirow[t]{2}{*}{ No. } & \multirow[t]{2}{*}{ Job title } & \multicolumn{2}{|c|}{ Professional experience } & \multicolumn{2}{|c|}{ Current use of social media } \\
\hline & & $\begin{array}{l}\text { Job } \\
\text { experience }\end{array}$ & $\begin{array}{l}\text { Storm } \\
\text { experience }\end{array}$ & $\begin{array}{l}\text { Crisis } \\
\text { communication }\end{array}$ & $\begin{array}{l}\text { Social Media } \\
\text { analytics }\end{array}$ \\
\hline $\mathrm{P} 10$ & Head of the rescue control center & 29 years & Kyrill (2007) & not implemented & not implemented \\
\hline P11 & Control center situation officer (press and public relations) & 16 years & $\begin{array}{l}\text { Eberhard (2019) } \\
\text { Ela (2014) }\end{array}$ & $\begin{array}{l}\text { Twitter } \\
\text { Facebook }\end{array}$ & $\begin{array}{l}\text { Manual screening } \\
\text { TweetDeck }\end{array}$ \\
\hline $\mathrm{P} 12$ & Head of the office management staff (press and public relations) & 9 years & Eberhard (2019) & Twitter & Manual screening \\
\hline P13 & Contact person (press and public relations) & 27 years & $\begin{array}{l}\text { Eberhard (2019) } \\
\text { Friederike (2018) }\end{array}$ & $\begin{array}{l}\text { Twitter } \\
\text { Facebook }\end{array}$ & $\begin{array}{l}\text { TweetDeck } \\
\text { Hootsuite }\end{array}$ \\
\hline P14 & Officer (press and public relations) & 35 years & $\begin{array}{l}\text { Eberhard (2019) } \\
\text { Ela (2014) }\end{array}$ & $\begin{array}{l}\text { Twitter } \\
\text { Facebook }\end{array}$ & $\begin{array}{l}\text { Manual screening } \\
\text { TweetDeck }\end{array}$ \\
\hline
\end{tabular}

Overall, the interviews lasted between 60 and $90 \mathrm{~min}$. Again, the interviews were transcribed according to the rules of Kuckartz et al. (2008). We then analyzed the interviews using the approach of deductive category assignment according to Mayring (2014). The categories and subcategories used for the manual classification of tweets were selected as predefined categories for the qualitative content analysis of the interviews. From the transcripts, we extracted the
Table 7 Structure and main questions of the second round of expert interviews

\begin{tabular}{|c|c|}
\hline Part & Main questions \\
\hline Introduction & $\begin{array}{l}\text { Sociodemographic data (age, job title, professional experience, } \\
\text { personal tasks) } \\
\text { Information about the emergency control room (responsibilities, } \\
\text { tasks, structure, equipment, types of crisis situations) }\end{array}$ \\
\hline $\begin{array}{l}\text { Information Processing Procedures in } \\
\text { Emergency Control Rooms }\end{array}$ & $\begin{array}{l}\text { Personal experience and tasks during the storms Dragi and } \\
\text { Eberhard } \\
\text { Information processing procedures in emergency control rooms } \\
\text { during natural disasters } \\
\text { - What different types of data do you observe in your control } \\
\text { center? } \\
\text { - From which sources do you receive information? } \\
\text { - How easy or difficult is it for you to find helpful information? } \\
\text { - In which situations would you like more information? } \\
\text { - Do you use social media use during disasters? If so, how do you } \\
\text { use it? }\end{array}$ \\
\hline Evaluation of Example Tweets & $\begin{array}{l}\text { General opinion of social media use during crisis situations } \\
\text { Evaluation of usefulness and trustworthiness of rated example } \\
\text { tweets } \\
\text { - Which data types do you think would be most useful in a crisis } \\
\text { situation? } \\
\text { - Information from whom would you trust? } \\
\text { - From which roles do you find the available information most } \\
\text { helpful? }\end{array}$ \\
\hline Conclusion and Future Social Media Use & $\begin{array}{l}\text { Future use of social media use } \\
\text { - Could you imagine using social media in future crisis situations? If } \\
\text { so, how? } \\
\text { - We have already talked a lot about data formats and data sources. } \\
\text { Are there any other aspects that might influence the usefulness of } \\
\text { tweets? } \\
\text { - What data would you ideally want to receive from Twitter? }\end{array}$ \\
\hline
\end{tabular}


opinions expressed about the usefulness of the selected tweets. By applying nominal category systems (Mayring 2014), we further distinguished between positive, negative, and ambiguous statements of the interviewees regarding the different categories of tweets.

\section{Results}

\subsection{Situation Awareness Requirements}

The goal-directed task analysis based on the first round of expert interviews resulted in a hierarchical chart consisting of the primary goal hierarchy and two individual branches including decisions and situation awareness requirements. All interviewees declared "the saving of human and animal life as well as the protection of property and cultural assets" as the overall operator goal in their profession. As illustrated in Fig. 2, the two major goals are divided into "sending of emergency forces" and "support of emergency operations". The detailed individual branches of the first and second major goal can be found in the electronic supplementary material.

Major Goal 1: Sending of Emergency Forces The first major goal presents the process from receiving the call to sending the first responders. To determine the required emergency forces, the operator first has to identify the exact location (P09). Related to this, the second interviewee said: "In the case of an emergency call, the first priority is to verify the place of operation. The reason for this is that if the conversation breaks off in between, then we have at least a place where we can send the emergency services" (P02). The situation awareness requirements differ based on the location the operator tries to identify. For example, when the conversation indicates an emergency situation in a building, the operator tries to gain information about the street, apartment and building. However, when the caller describes a situation in a forest, this activates a different mental model and the operator's approach on the identification of the location changes. There is also the possibility that the callers on the phone do not know where they are or that they unintentionally give misdirecting information (P01, P06). These are situations in which the operator must use the described features in the caller's environment, such as bus stops or churches within sight. Another important situation awareness requirement regarding the location is the accessibility of the scene (P03). It is possible that a person is trapped in a car or in a building which requires additional rescue tools to be taken into account when selecting the emergency forces.

Fig. 2 Primary goal hierarchy

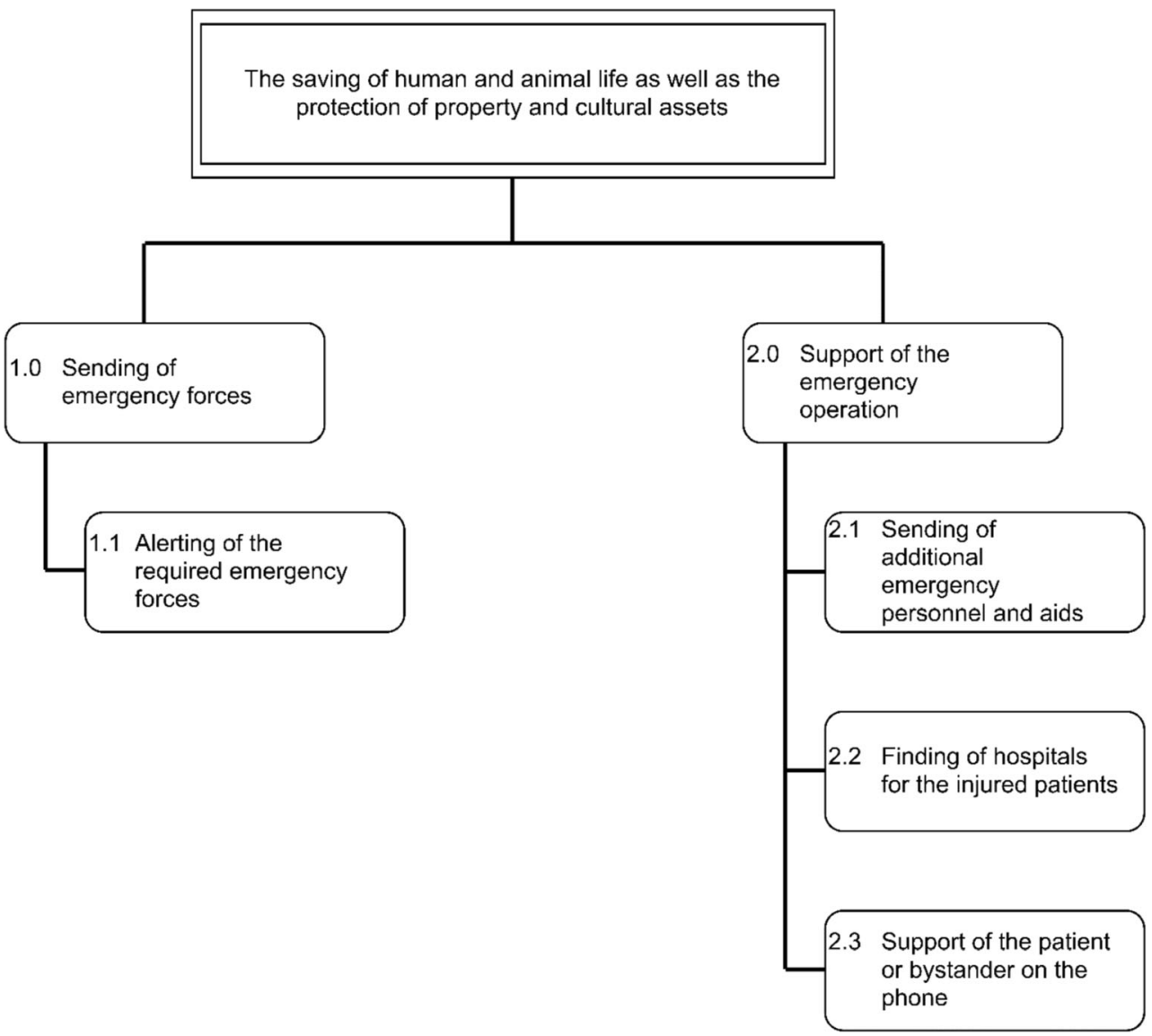


After gaining the required situation awareness information to identify the location and the accessibility, the operator needs to understand the situation to select the right forces. Similar to the information needed to determine the location, what the operator needs to know depends heavily on the nature of the emergency. For example, in case of fire the operators need information about the color of the smoke, the size and location of the fire, the surroundings, and the affected people to understand the current situation and predict the possible spreading of the fire ( $\mathrm{P} 01, \mathrm{P} 02)$. For an operation involving injured or sick people, the necessary information focuses more on the condition of the patient and the needed medical treatment (P03, P04). With the required information to locate the emergency, understand the situation and verify the responsibility, the operator is able to select a keyword according to which the system makes a suggestion regarding the needed emergency vehicles.

Furthermore, the operators need information to determine the necessity of additional special emergency forces. Operators often face situations where special tools or specially trained forces are required, for example, when a person is trapped or certain substances are needed to extinguish a fire. One interview partner said: "Special means or special vehicles or forces are always required when the case is different than the norm. It already starts when we have a person in the water" (P06). The same applies to the choice of additional authorities. If the operation involves situations the emergency forces are not trained for, the emergency operator may also involve other authorities trained for such situations. With all the above-mentioned situation awareness requirements, the operator can choose the emergency forces, special vehicles with the required tools, and authorities that are needed for the operation. The last step towards achieving the first major goal is to alert the selected emergency forces. However, this is an automated process and therefore no additional situation awareness requirements are needed.

Major Goal 2: Support of the Emergency Operation The second major goal involves the support of the emergency operation and includes three subgoals. The first subgoal is achieved by sending additional emergency forces and contains four decisions that require information similar to the decision of the initial selection of the required emergency forces. The main difference is that within the second major goal, the situation awareness requirements for these decisions are mostly obtained from the first responders and not from the callers (P04, P05). However, it is also possible that this information may be received from other callers, although this case occurs less often. The obtained information helps the operator to understand the lack of emergency forces as well as the mental condition of first responders and bystanders to forecast future demand. With this projection, additional forces, special vehicles, other authorities and psychosocial care can be sent after the arrival of the first responders at the scene of emergency.

The sending of further forces or aids is not the only way in which an operator can support an emergency operation. It often happens that these situations involve injured or ill people that need to be stationed in a hospital (P01). Since the first responders are busy with the handling of the accident, the operators are responsible of finding a suitable hospital. To achieve this, operators are dependent on the information they receive from the first responders since they decide if a person needs medical treatment. There are different situation awareness requirements to identify the adequate clinic. The most important one is the availability of the required equipment for appropriate medical treatment. For example, if a person has suffered a head injury in an accident, the hospital ought to have a neurological department. Additionally, the operator and first responders need to consider the preference of the patients. If they designate a clinic to which they wish to be transferred to and that clinic has the appropriate equipment, the emergency services will try to comply with the request. This preference may be based on factors such as proximity to home or family and experience or pre-treatment in the facility, which are also aspects that the operator considers even if the patient does not have a preferred clinic. The support of the operation is not only provided by assisting the emergency forces, but also by helping the person on the phone before the arrival of the forces. This help can include the instruction for medical treatment like cardiopulmonary resuscitation (P01). The situation awareness requirements to understand the need of this support on the phone is based on the operator's comprehension of the situation and the information gained in the conversation. It is possible that the callers request guidance because they do not know how to behave or that the operator understands that the caller is overwhelmed by the situation and predicts the need for an instruction.

\subsection{Usefulness of Tweets for Situation Awareness Support}

The interviewed fire fighters preferred to keep social media analytics separate from the working field of the emergency operators. One fire fighter stated that, "it is not the task of the control center to access the Twitter channel" (P11). In their daily social media work, the interviewees network and extend their range, e.g. by connecting and subscribing to official local channels, such as the police, press agencies, and traffic companies. During a crisis, the social media channels are operated alongside the normal press work and four interviewees already use social media to monitor ongoing crisis situations. If they find relevant information, they pass it on to the emergency management and the control room. Most interviewees saw a lot of potential in the automated analysis 
of large amounts of social media data and described the analysis of Twitter data as useful and inevitable while still mentioning some concerns regarding the trustworthiness. Regarding the content of a tweet, the interviewees generally preferred detailed, concrete and up-to-date information about the situation. They also mentioned the importance of hashtags, since they are monitoring manually and use the official hashtags, which they either registered or distributed themselves, to find relevant information. Credibility of the source was also very important to emergency managers and was perceived ambiguously by them. Concerning the different communicator's roles, official sources were viewed as trustworthy, e.g. transport services (Deutsche Bahn, the national railway operator) or governmental organizations (German Meteorological Service). In contrast, the interviewees were concerned with the credibility of private persons, while also stating that trustworthiness depended on the actual case and they take every hint seriously. Finally, most interview partners agreed, that the data format is not as important as the content itself. One person said: "Whether it is a picture, a text or a video is irrelevant" (P12). However, all interviewees rated the specification of an exact location as crucial for planning operations and sending task forces. Table 8 summarizes the types of tweets that were described as useful and trustworthy by the interviewees.

\subsection{Conceptual Augmented Reality Design}

The goal-directed task analysis is a technology-independent method that focuses on identifying the important goals, decisions, and situation awareness requirements of operators (D. G. Jones et al. 2012). A goal-directed task analysis can be used to determine what operators would ideally like to know to meet their goals, even if that information is not available with their currently used technology (Endsley et al. 2003). Therefore, the situation awareness requirements of the goaldirected task analysis can be used to explore possibilities of improving the presentation of information with any kind of technology (D. G. Jones et al. 2012). Based on previous literature, we identified augmented reality as a promising technology that might improve situation awareness in emergency control rooms (Brunetti et al. 2015; Luchetti et al. 2017; Nunes et al. 2019). In the following, we propose a conceptual augmented reality design considering the identified situation awareness requirements in the first round of expert interviews, the identified useful and trustworthy social media information identified in the second round of expert interviews, and the proposed situation awareness design principles from Endsley et al. (2003). We evaluated and improved the conceptual design based on the results of a workshop with two situation awareness and two augmented reality design experts.

Table 8 Usefulness for situation awareness and trustworthiness of the categories

\begin{tabular}{|c|c|c|c|}
\hline Category combinations & Useful? & $\begin{array}{l}\text { Trust- } \\
\text { worthy? }\end{array}$ & Reasoning for evaluation \\
\hline $\begin{array}{l}\text { Traffic information from } \\
\text { transport businesses }\end{array}$ & yes & yes & $\begin{array}{l}\text { Provides situation information that simplifies the estimation of traveler movements and it } \\
\text { not yet provided by another official information source } \\
\text { "As firefighters, we don't know what it looks like on the rails and it is important to know if } \\
\text { trains are no longer running, and therefore many people may be waiting at stations" } \\
\text { (P12). }\end{array}$ \\
\hline $\begin{array}{l}\text { Eyewitness reports from private } \\
\text { persons }\end{array}$ & yes & ambiguous & $\begin{array}{l}\text { Interested in finding undiscovered places of action quickly, since an undiscovered operation } \\
\text { could present a danger for civilians. However: concerns regarding the credibility } \\
\text { "If you can see that } 10 \text { people tweet from one place, because the dike threatens to break, } \\
\text { then I have to look at it" ( } \mathrm{P} 14) \text {. }\end{array}$ \\
\hline $\begin{array}{l}\text { Weather information from } \\
\text { government organizations }\end{array}$ & ambiguous & yes & $\begin{array}{l}\text { Redundancy with existing information } \\
\text { "We receive information for our city directly from the German Meteorological Service" } \\
(\mathrm{P} 10) \text {. }\end{array}$ \\
\hline $\begin{array}{l}\text { News from media organizations } \\
\text { and journalists }\end{array}$ & no & yes & $\begin{array}{l}\text { Redundancy with existing information } \\
\text { "The official pictures of the Tagesschau and of the WDR are mostly pictures that they have } \\
\text { from us, because we are on the scene" (P14). }\end{array}$ \\
\hline $\begin{array}{l}\text { Weather information from } \\
\text { media organizations }\end{array}$ & no & ambiguous & Redundancy with official statements from the meteorological center \\
\hline $\begin{array}{l}\text { Traffic information from media } \\
\text { organizations }\end{array}$ & no & ambiguous & Redundancy with official statements from transport businesses \\
\hline Emotion tweets & no & - & Not relevant for achieving situation awareness \\
\hline Action tweets & no & - & $\begin{array}{l}\text { Not relevant for achieving situation awareness } \\
\text { "Warnings from others are less relevant to us as we are already alerted and prepared" } \\
(\mathrm{P} 12) .\end{array}$ \\
\hline Opinion tweets & no & - & Not relevant for achieving situation awareness \\
\hline
\end{tabular}


Table 9 provides an overview about the participants of the workshop.

During the workshop, we demonstrated the design to the participants and asked them to discuss the following six questions: 1) How could the design enhance the situation awareness of an emergency operator? 2) How well does the design implement design principles that you are familiar with? 3) What are the innovative aspects of the design that distinguish it from other solutions in the literature or on the market? 4) What kind of technological challenges do you see in implementing this design? How could these challenges be solved? 5) What do you think is the added value of social media data for achieving situation awareness in control rooms? 6) What added value do you think augmented reality offers compared to the existing solutions in control rooms? In the following, we present our conceptual design and feedback from the situation awareness and augmented reality design experts.

The first design principle of organizing information around goals is already met by the currently used systems, as the control centers we visited used around 6-7 displays to present various software programs related to different goals. For example, there was one display that presented the information regarding the location of the emergency, one contained information gained from the emergency call, and another display was used to select the keyword and emergency vehicles (P01, P05). This division of visuals should also be implemented in augmented reality to fulfill the first design principle. However, augmented reality allows for more freedom when it comes to organizing information around goals: "If you simply have to drag and drop the information with your hands, you can be a lot faster with grouping the information and categorizing it and get a nice overview" (AR02). As the operators mentioned, the determination of the location is the most important situation awareness requirement to send the required emergency vehicles. Therefore, we are going to use the subgoal "Identification of the Location" as an example to show how an augmented reality interface could look like. The proposed interface includes a map and customizable filter options to display the types of tweets that were described as useful and trustworthy in the second round of interviews (see Fig. 3).

The map provides the operator with an overview of the area of the emergency scene including the different tweets depending on the type of crisis. The selection of the Twitter data that can support the operation could be accomplished by defining keywords for each type of crisis. The location could be derived by accessing the georeferencial data if provided by the user, the author location stated in the user profile, or by extracting mentioned locations from the tweet text. To differentiate the tweets from the marked place of the emergency, the tweets could be displayed as colored pins. The usage of customizable filter options is mandatory to assure that the operator using the system is not overwhelmed by the amount of crisis-related tweets. In our suggestion, the operator would be able to select different filter options by touching the document icon in the top right corner. By touching one of the pins representing a tweet, the operator could open a small window with a detailed view of the tweet. This view could contain information about the author and the tweet content. According to one of the situation awareness experts, "the design also considers the principles of Shneiderman's information-seeking mantra very well by allowing operators to establish an overview first, then zoom and filter to get details on demand" (SA02). Pictures and videos of the scene that were posted on social media were perceived as very useful by some subject matter experts and could increase the operator's situation awareness. One interviewee explained: "Sometimes it is a matter of seconds. To have a system that picks up videos and pictures and shares them with the emergency services would be very useful for the first responders who does not know anything before coming to the scene" (P07). The situation awareness experts confirmed the importance of pictures and videos because "verbal communication can't always answer in a very good way what you as an emergency dispatcher want to know. For instance, if there is a fire. They want to know what the color of the smoke is. That is kind of hard for the caller to explain" (SA02). The detailed view of the tweet could further include different indicators for the relevance of the content and trustworthiness of the author.

The second principle recommends the direct presentation of the level 2 situation awareness requirements to assist with the comprehension. To support the "Identification of the location", our user interface includes a map of the affected area based on the entered address of the emergency with information about the surroundings. This map could contain further level 2 information about traffic jams, conditions of the streets, access to the location,
Table 9 Overview of workshop participants

\begin{tabular}{|c|c|c|c|}
\hline No. & Gender & Job title & Research focus \\
\hline SA01 & female & $\mathrm{PhD}$ Student & $\begin{array}{l}\text { Shared situation awareness, Additional experience: worked as an } \\
\text { emergency operator for ten years }\end{array}$ \\
\hline SA02 & male & $\begin{array}{l}\text { Post Doctoral } \\
\text { Researcher }\end{array}$ & Social media and mobile apps for situation awareness \\
\hline AR01 & male & $\mathrm{PhD}$ Student & Multimodal augmented reality interaction design \\
\hline AR02 & female & $\begin{array}{l}\text { Post Doctoral } \\
\text { Researcher }\end{array}$ & Immersive technologies for skill development \\
\hline
\end{tabular}



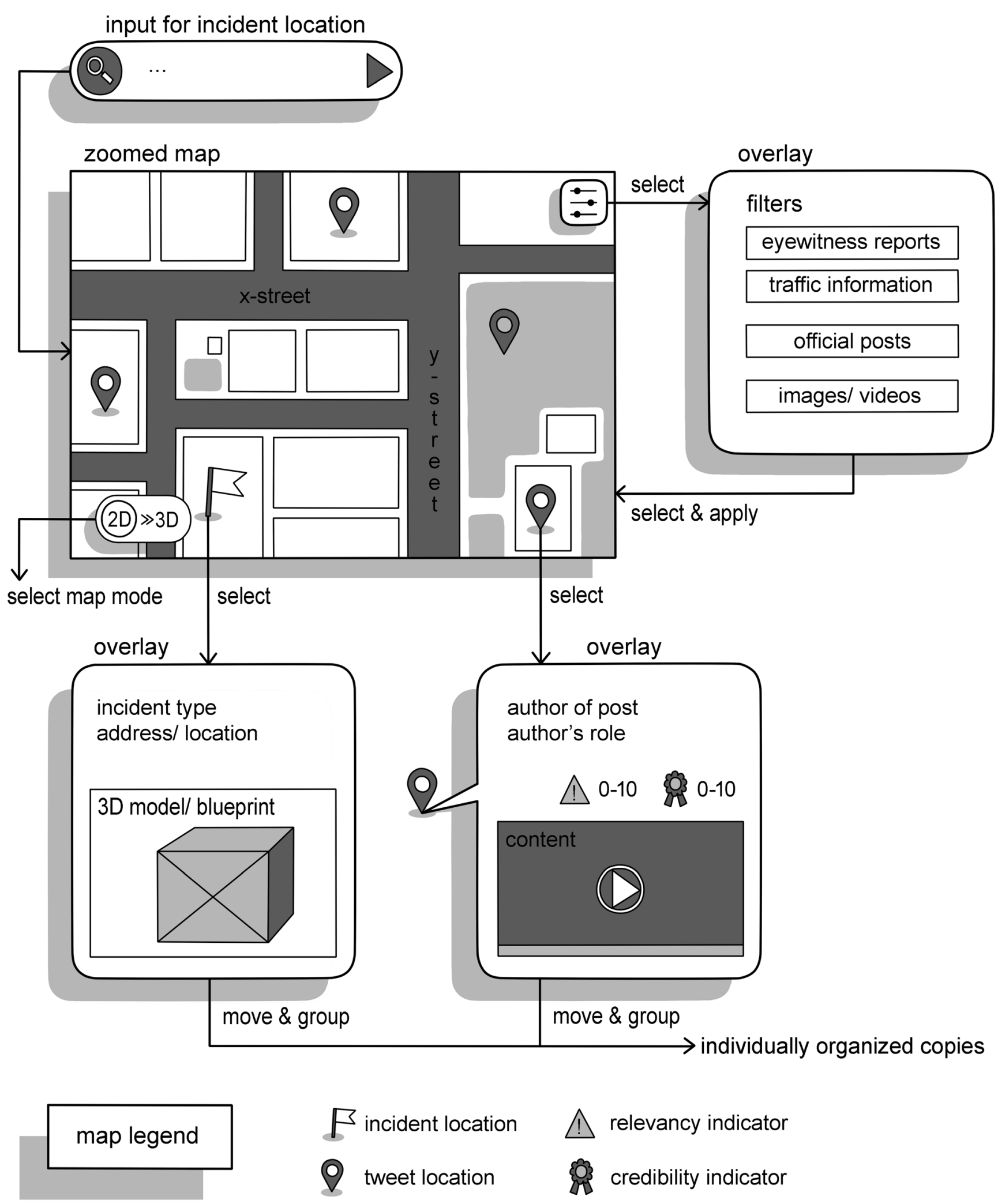

Fig. 3 Conceptual wireframe design for an augmented reality application in emergency control rooms

and the environment of the emergency. To increase their understanding of the situation the dispatchers already use Google Street View (P05, P06). The situation awareness experts also perceived that an additional 3D view of the map supports comprehension because, "if you get some videos and you cannot fully comprehend from which angle or perspective it was taken, you 
can get additional insights if you have an additional $3 D$ perspective" (SA01). The other situation awareness expert added: "I think the 3 D perspective can sometimes be overwhelming, so two dimensions are good for the overview and three dimensions on demand when you need additional information" (SA02). Especially the usage of 3D models was seen as useful. One emergency operator said: "I personally already use Google [...] that is already a kind of $3 D$ thing. [...] But it has to be easier. Google is not that easy, it cannot be done just like that and for us it has to be fast and secure and that is not the case on the Internet with such open software" (P06). These 3D building models could present additional information regarding the accessibility of the scene or display the exact location like the floor where it burns in the case of a fire. For example, the windows of the room with the fire could be illustrated with the color red to make them salient while the entrance and emergency exits are presented in green. This way, the used colors also activate mental models and schemata of the emergency operators. However, this still represents a technical challenge as one of the augmented reality experts explained: "If you want to have exact information perhaps where the emergency exits are, then you need some other data sources. Perhaps integrate data from the building or city departments" (AR01).

The third principle suggests providing assistance for level 3 situation awareness projections. This can be achieved through displays that present changes in parameters over time. One of the augmented reality experts saw huge potential in using the 3D building models to display changes over time: "For example, if some parts of the building broke down and you have pictures from social media. I think this could be really difficult but also an interesting challenge for future research. Maybe there is a way of getting into the perspective of where the social media photo was taken. And then use the photo to lay it over the $3 D$ perspective you have" (AR02). Currently, the control rooms use large monitors in the front of the room to display the changes of conditions in different areas (P01). For instance, one of these screens shows a weather map which presents possible storm incidents, climatic changes, and other variables. This representation of the weather parameters helps the dispatchers to recognize possible problems caused by storms at an early stage and prepare themselves accordingly. This representation already fulfills the third principle, however, augmented reality would allow the users to place this information as they like since the representation in the virtual environment does not depend on the physical equipment in the room. This possibility was also seen by one of the interview partners who said: "We do not use such a thing [augmented reality]. But I think that would be a good thing, because we are building a situation wall, for example, for major damage situations, in which a map is presented that shows the burning objects and the units that are present in an emergency. [...] To present such a situation wall digitally with simple means would be a dream come true" (P06).
The fourth design principle highlights that the support of global situation awareness is important. This can be achieved by giving the user an overview without restricting their access to support the selection of the highest priority goal. Augmented reality offers the opportunity to place a large number of virtual windows in a beneficial way, which ensures that the operators focus on the most important elements without creating an attention narrowing effect. In comparison to the currently used 6-7 monitors, augmented reality allows a larger overview which supports the global situation awareness. Therefore, excessive menuing and windowing with specific data in order to obtain information is not necessary. It is possible to provide the needed knowledge in different windows at the same time allowing the simultaneous perception without overloading the user with information. Therefore, the user interface should contain multiple elements, each providing the situation awareness information necessary for the respective decisions.

However, as described in the fifth principle, it is important to find a balance between the goal-driven and data-driven processing. An extreme tendency to one of the processing types is detrimental for the operator's attention and affects the situation awareness in a negative way (Endsley et al. 2003). The design in augmented reality should provide an overview over the important elements without overloading the user. Too few elements, on the other hand, can cause the user to have attention narrowing since not every important information can be perceived. The above-mentioned combination of elements already considers the fourth principle and thereby supports the data-driven processing. To enhance the goal-driven processing, an augmented reality system should make the high-priority elements conspicuous to the user, for example, by using different colors or a specific arrangement in the virtual environment.

According to the sixth design principle, it is important to make critical cues for schema activation salient. As mentioned before, mental models and schemata are important to achieve high level situation awareness. First of all, it is important to identify the cues that activate the mental models. For instance, control centers and hospitals use the traffic light colors along with the colors blue and black to prioritize injured patients of mass casualties ( $\mathrm{P} 03, \mathrm{P} 04)$. Green indicates the lightly injured, yellow marks the badly injured, and red the severely injured (P03). The additional color blue marks the patients who cannot be treated and black symbolizes casualties (P06). Since the red marked ones have to be treated faster, this prioritization helps the operators to organize the treatment accordingly (P03). These colors can be used as critical cues to activate specific mental models and schemata. For example, the previously mentioned relevance or trustworthiness indicators for the tweets could also define different colors for the pins on the map allowing the operator to react faster on the more important information.

Another way of supporting the operator's situation awareness is described with the seventh principle, which advises to take advantage of parallel processing. If it is possible, the system 
should provide not only visual, but also acoustic or haptic information. Since most information is gained through the emergency call, the auditory channel is already used in this work environment (P01, P02). To improve the situation awareness visually, the previously mentioned $3 \mathrm{D}$ building models could be utilized. Furthermore, one augmented reality expert highlighted the importance of a multimodal interaction approach: "When you use gestures in the air, you don't have any feedback. This means the situation awareness could be reduced because the operators have to use mental capacities for just controlling the system" (AR01). Therefore, we suggest enabling operators to switch between hand gesture and eye gaze interaction with visual feedback. The eighth design principle emphasizes the careful use of information filtering. The reduction of information is often times associated with the thought that it would lead to a reduction of information overload and an improved situation awareness. But this reduction is more likely to inhibit the situation awareness of the operator by removing important information (Endsley et al. 2003). The recommended approach is to give the user the opportunity to decide what kind of information he or she wants to see. One of the situation awareness experts suggested that the design could not only offer customized filter options for different types of tweets but also for different data sources: "It could serve as a very good extensible base platform. When I was in contact with fire departments they were also concerned about drones. And you can extend your concept if you have some drones deployed and you click on a drone and see the live footage" (SA02).

\section{Discussion}

\subsection{Situation Awareness Requirements}

The first round of expert interviews and the goal-directed task analysis were conducted to answer our first research question and allowed us to identify the goals, decisions and situation awareness requirements that need to be considered when designing a situation awareness support system for emergency operators. With this method, we were able to determine "sending the emergency forces" and "supporting the emergency operation" as two major goals that need to be accomplished to achieve the overall operator goal which is "the saving of human and animal life as well as the protection of property and cultural assets". The different subgoals and decisions to achieve the first major goal focus on the operator's understanding of the situation and the selection of the appropriate emergency forces. To achieve the first major goal, the operator requires information about the location of an emergency, the accessibility of the emergency scene, information about what exactly happened at the scene, and information about the medical condition of affected people. We found that the detailed description of the emergency location constitutes the most important situation awareness requirement for emergency operators because this information enables them to send emergency forces even if all other relevant information is missing. It is especially critical that the emergency operators are mostly dependent on the information gained from the person who made the emergency call to make decisions about the sending of emergency forces. Thus, the integration of social media data into the control room work environment could be especially useful if the caller has only provided incomplete information. The second major goal focuses on sending additional emergency forces and aids to the scene, selecting an appropriate hospital for injured persons, and assisting callers with instructions on the phone. To achieve the second major goal, the operator requires information about the required number of emergency forces at the scene, the required knowledge, skills and authority to deal with extreme situations, the required special vehicles and tools, information about the mental condition of first responders and bystanders at the scene, information about the medical condition of affected persons, and information about the knowledge of the caller. The situation awareness requirements necessary to support the emergency operation are different from those required for the first major goal of sending emergency forces, since they are mostly obtained from the first responders at the scene.

These situation awareness requirements are essential to design a system that can support the operator's situation awareness. To obtain these requirements, we applied the goal-directed task analysis technique that was first demonstrated in the aviation domain and afterwards tested in different work environments, for example, in industrial plants (Paulusová and Paulus 2018) or within the army brigade (Bolstad et al. 2012). In the emergency field, there were similar approaches to identify the user requirements in emergency management such as the applied cognitive task analysis used by Pfaff (2015) or the hierarchical task analysis used by De Leoni et al. (2007). Compared to these approaches, our method resulted in a more detailed and comprehensive view of the required information to achieve a good job performance as an emergency operator. For example, the hierarchical task analysis utilized by De Leoni et al. (2007) revealed the different goals required to achieve the overall operator goal without describing the different decisions that need to be made. Since goals can involve multiple decisions to be achieved, it is important to also include them in addition with the required situation awareness information to completely understand the requirements in a specific work environment. The conducted expert interviews in combination with the goal-directed task analysis allowed us to illustrate the decision-making process of the emergency operators in a very detailed way. However, there are also studies that utilized the goal-directed task analysis in the emergency field. For example, the goal-directed task analysis was applied to identify situation awareness requirements during a single event like the attack on the World Trade Center (Dawes and Cresswell 2004). Thus, the obtained situation awareness requirements are not universally applicable like the results of our comprehensive 
analysis. Furthermore, Humphrey (2009) created a hierarchical chart using the goal-directed task analysis which included every stage and step involved in an emergency situation. The major goals in this study start with the prevention/deterrence of a crisis and end with the last steps of the recovery/remediation after a crisis situation. A similar broad view on the field of emergency management was also created by R. E. T. Jones et al. (2010) in which they additionally included major goals like the detection of bio events. Compared to our results, the decisions and goals are in some occasions akin but since we focused on the specific role of emergency operators, we were able to identify a considerable larger number of situation awareness requirements. In summary, our results represent a novel view with unprecedented detail of the situation awareness requirements of operators working in control rooms.

With the obtained situation awareness requirements it is possible to compare the information needed with the information available through social media. This allows us to determine how social media data can be used to further support the operator's situation awareness. For example, the geolocation of an eyewitness who posted a tweet about a certain crisis can provide useful information to achieve the subgoal "Identification of the location". Since most users deactivate the sharing of their geolocation, this information could in many cases also be obtained through the post's content by using text and image analysis or integrating data from other social networks like YouTube or Facebook. For example, pictures or videos posted from the emergency scene could obtain information regarding the accessibility of the scene and details about the location which the operator did not receive during the initial emergency call. This information could further enhance the understanding of the situation which would make the decision-making easier. Information contained in the post could also support the operator in determining what exactly happened at the emergency scene. For example, user generated tweets from an emergency scene could be extracted by existing text mining tools and presented in an apprehensive way, so that emergency operators could estimate the threats of a situation, how many civilians are involved or how accessible the location is. Furthermore, traffic information posts from transport business organizations could provide information about where additional emergency forces might be needed. Similar to the location, the provided information can enhance the user's understanding of the situation, and thus the situation awareness. In combination with a time series variation analysis of the disaster damage, the relevant tweets will not only be useful during realtime operations but also to discuss a disaster mitigation plan.

\subsection{Usefulness of Tweets for Situation Awareness Support}

The second round of expert interviews was conducted to answer our second research question and allowed us to identify the types of tweets that emergency operators perceived as useful to achieve situation awareness. Our study confirms previous research results stating that emergency management organizations in Germany are still not incorporating the full potential of social media analytics (Eismann et al. 2016; Stieglitz et al. 2018c; Tapia et al. 2013). We found that traffic information from transport business organizations is perceived as particularly useful and trustworthy. One of the situation awareness experts explained: "We have this road company and they have this official map where you could get this information from. But they are not too quick with putting in the information. It's not very implemented in their procedures I think. Maybe in some huge events, social media could be faster" (SA01). In addition, the interviewees described eyewitness reports as useful but questioned the trustworthiness of private persons. Most tweets were rated as not useful, e.g. posts from Twitter profiles of media channels as well as emotional, action, and opinion tweets. However, in our view this represents an advantage for the integration of social media data into the work environment of emergency operators. If there is only a small number of tweets that is actually perceived as useful, filter algorithms can be used to exclude the large amount of irrelevant information. This way, the integration in of social media data into control rooms can provide an added value without causing information overload, which would negatively affect situation awareness. Consequently, filter strategies that specifically display traffic information and eyewitness reports are needed to improve the usefulness and increase the adoption of social media analytics solutions for emergency management. In previous research, it has already been proposed that "a customization of filtering algorithms for the needs of emergency management agencies might be needed for them to respond to their specific crisis situations" (Stieglitz et al. 2018c). Related to this, the eighth design principle for situation awareness demands the careful use of computerdriven filtering and recommends the use of customizable filter options (Endsley et al. 2003). Our research also revealed that individual operators have different perceptions of the usefulness and trustworthiness of different types of tweets. For example, some interview partners perceived weather information from media organizations as relevant while others considered them to be redundant. We therefore suggest to provide customizable filter options allowing emergency operators to adapt the visualization of social media data according to their needs.

The first step towards the development of filter strategies is improving the data collection process in existing algorithms by selecting only useful information for further processing and visualization. While there are already multiple approaches that focus on the extraction of eyewitness reports (e.g. Zahra et al. 2020), the development of algorithms to extract information from relevant business organizations such as railway traffic companies has been neglected so far. In this matter, our findings reveal that new crowdsourcing approaches or machine learning algorithms are needed. In a second step, the filtered set of relevant social media data needs to be visualized to support the situation awareness of emergency operators. As we identified the 
informativeness as the main attribute of useful posts, the visualization of social media data should be combined with a relevancy indicator that highlights the most important tweets. To assess the relevancy, the number of retweets can be considered, as previous research concluded that users mostly retweet posts that are either from official sources or from eyewitnesses (Starbird and Palen 2010). The interviewees also mentioned other aspects that could contribute to the relevance indicator: These include the @-function that marks messages directly addressed towards emergency management organizations, searching images in Google Pictures to ensure that they are up-to-date or have been used before, and the style of writing that can identify concrete and detailed information. The latter was used by Verma et al. (2011), who found that actionable tweets were objective and formal and could identify disaster relevant posts with this method. As not only relevancy but also trustworthiness is important to emergency operators, the relevant social media data should also be visualized in combination with a trustworthiness indicator, e.g. a traffic light system. Factors that could be integrated into such an indicator could be the verified badge that Twitter offers for accounts of public interest. Other criteria like the author's description and name, number of followers, formal language, and confirming the person's location could be applied for accounts without this label. Trustworthy networks could be organized through subscriptions to local officials and Twitter's list function, which can be used to incrementally organize private persons' accounts, whose trustworthiness might already have been proven in past events, into content groups (e.g. "local population") and monitor their tweets without subscribing to them. To the best of our knowledge, the combination of the previously named indicators for relevance and trustworthiness have not been implemented in previous research, although emergency managers often associate their willingness for the adoption of social media analytics with these two aspects (Zade et al. 2018). Most algorithms use informativeness as main criterion for data extraction and incorporate relevancy in their selection process. For instance, there are algorithms using the increase of attention and retweets to identify crisis-related tweets (Hiltz and Plotnick 2013; Starbird et al. 2012) and sorting their tweet list according to the number of retweets (Ludwig et al. 2015b). Other researchers rather focus on the trustworthiness of social media information (Lazreg et al. 2018; Tapia et al. 2013). Related to this, Hiltz et al. (2020) identified a rating of trustworthiness as one of 16 features that experts would find useful in software to support social media use in emergency management. Our proposed indicators can inform the implementation of this important feature.

\subsection{Conceptual Design Augmented Reality Design}

To answer our third research question, we synthesized the results and proposed a conceptual augmented reality design that integrates social media data into control rooms. The design includes a customizable filter function based on the previously presented filter strategies. Thus, the proposed design integrates only useful and trustworthy Twitter data so that situation awareness can be increased without creating information overload. At the same time, the design fulfills the eight design principles for situation awareness (Endsley et al. 2003) and addresses the situation awareness requirements of emergency operators we identified through the goal-directed task analysis. In previous research, there are already situation awareness support systems that integrate social media data and provide support for emergency responders; however, the needs of emergency operators have not been addressed so far. As a result, our proposed design can support situation awareness in a new field of emergency management. Furthermore, we emphasized a user-centered approach by conducting interviews with experts from the application domain to secure the usefulness of our design. There have also been other researchers who derived requirements for social media analytics from interviews with emergency managers (Hiltz et al. 2020; Stieglitz et al. 2018c) and the tool CrowdMonitor, for instance, was also developed based on expert opinions (Ludwig et al. 2015b). Nevertheless, the development of a design has not been combined with the goal directed task analysis, which ensures that our design fits the specific needs of emergency operators. Similarly to other approaches, e.g. CrowdMonitor, Senseplace2, Scatterblogs, Whistland or CrisMap, our design includes a map where emergency tweets can be located in a well-structured arrangement. However, we have deliberately avoided to include tweet lists or timelines in our design as it can be found in Whistland or Senseplace2, so that the emergency operators will not experience information overload. In addition, our conceptual design includes visualization using augmented reality technologies, which enable quick interpretation (Luchetti et al. 2017) and decision making through the unique presentation (Chandler et al. 2015; ElSayed et al. 2016). Regarding other implementations for augmented reality, mobile solutions like Smart Augmented Field of Emergency or THEMIS-AR have been designed to guide, inform and connect first responders, but they do not incorporate social media data, even though it was found to increase situation awareness. One of the augmented reality experts further highlighted how our proposed design extends previous research: "Many augmented reality applications are just 2D screens with many layers. But what you mostly don't have is a bird eye view where you have a look at the scenery from top and can walk around and can enter different perspectives" (AR01). With our design, we think outside the patterns of 2D screens and propose to implement a $3 \mathrm{D}$ view of the map on demand which could help the operators to interpret the perspectives of social media pictures and videos.

\section{Conclusion}

In the present study, we examined the potential of social media and augmented reality to enhance the situation awareness 
of emergency operators working in control rooms. In a first step, we conducted a goal-directed task analysis to identify situation awareness requirements of emergency operators. We were able to determine that information about the location constitutes the most important requirement for emergency operators to achieve situation awareness. In a second step, we collected Twitter data during two storms in Germany and conducted expert interviews with emergency operators to evaluate the perceived usefulness of Twitter data for achieving situation awareness. The interviews revealed that traffic information from transport business organizations and eyewitness reports from private persons were rated as most useful. In contrast, other types of informational tweets as well as emotion, opinion, and action tweets were either evaluated as not useful or trustworthy enough to be integrated into control rooms. In a third step, we synthesized our results by proposing filter strategies for social media data and a conceptual augmented reality design that illustrates how useful and trustworthy social media data could be integrated into control rooms. We evaluated and improved our design based on the results of a workshop with situation awareness and augmented reality experts.

With our research, we contribute a hierarchical overview about the goals, decisions, and situation awareness requirements of emergency operators that has not been presented in such a detailed form, yet. The identified requirements serve as an important foundation for the design of situation awareness support systems for control rooms in the future. We further shed light upon the potential of emerging technologies such as social media and augmented reality for emergency operators while previous studies mostly focused on other actors such as emergency response teams in the field. In addition, we propose criteria that can be used to develop filter algorithms for extracting eyewitness reports and traffic information from transport business organizations. So far, most studies either focused on extracting eyewitness reports or informational tweets from trustworthy sources. However, we found that many informational tweets from trustworthy sources were not perceived as useful by emergency operators, and thus we highlight the need for more targeted social media filter algorithms.

Our research has some limitations. First, the results might not be representative of the whole emergency management landscape due to the small sample size and restriction to emergency operators working in control rooms of German fire departments. To validate the results, future studies should examine whether different types of emergency agencies worldwide perceive the situation awareness requirements and usefulness of social media data in the same way. Second, the usefulness of Twitter data was discussed with the emergency operators based on original tweets collected during a storm event in Germany. However, retweets and replies might also include relevant information and could be examined in future research. Furthermore, it might be conceivable that the perceived usefulness of Twitter data differs depending on the type and severity of the crisis situation as well as the usage patterns of Twitter in a given country. Related to this, future studies could also investigate whether the perceived usefulness of tweets depends on the different stages of emergency management (e.g. preparation, response, and recovery). Third, we proposed a conceptual design based on the insights gained through the goal-directed task analysis and expert interviews. The subject matter experts were not experts on interactive systems, therefore we invited situation awareness and augmented reality experts to provide further feedback on the design. Furthermore, the implementation and evaluation of the design regarding its usefulness for enhancing situation awareness and reducing information overload of emergency operators represents another avenue for further research. Nevertheless, the statements of our interview partners and workshops participants allow us to conclude that the control room work environment constitutes a promising application area for social media and augmented reality technologies.

Supplementary Information The online version contains supplementary material available at https://doi.org/10.1007/s10796-020-10101-9.

Funding This study was funded by the European Union's Horizon 2020 research and innovation programme under the Marie Skłodowska-Curie grant agreement No 823866. This study was also funded by the German Academic Exchange Service and the Norwegian Research Council (Norges forskningsråd) with grant \#294818.

\section{Compliance with Ethical Standards}

Conflict of Interest The authors declare that they have no conflict of interest.

Open Access This article is licensed under a Creative Commons Attribution 4.0 International License, which permits use, sharing, adaptation, distribution and reproduction in any medium or format, as long as you give appropriate credit to the original author(s) and the source, provide a link to the Creative Commons licence, and indicate if changes were made. The images or other third party material in this article are included in the article's Creative Commons licence, unless indicated otherwise in a credit line to the material. If material is not included in the article's Creative Commons licence and your intended use is not permitted by statutory regulation or exceeds the permitted use, you will need to obtain permission directly from the copyright holder. To view a copy of this licence, visit http://creativecommons.org/licenses/by/4.0/.

\section{References}

Ahmed, A. (2011). Use of social media in disaster management. Paper presented at the international conference on information systems. China: Shanghai. 
Alam, F., Ofli, F., \& Imran, M. (2020). Descriptive and visual summaries of disaster events using artificial intelligence techniques: Case studies of hurricanes Harvey, Irma, and Maria. Behaviour \& Information Technology, 39(3), 288-318.

Aupetit, M., \& Imran, M. (2017). Interactive monitoring of critical situational information on social media. Paper presented at the international conference on information Systems for Crisis Response and Management, Albi, France.

Avvenuti, M., Cresci, S., Del Vigna, F., Fagni, T., \& Tesconi, M. (2018). CrisMap: A big data crisis mapping system based on damage detection and geoparsing. Information Systems Frontiers, 20(5), 9931011.

Azuma, R. T. (1997). A survey of augmented reality. Presence: Teleoperators and Virtual Environments, 6(4), 355-385.

Basu, M., Bandyopadhyay, S., \& Ghosh, S. (2016). Post disaster situation awareness and decision support through interactive crowdsourcing. Procedia Engineering, 159, 167-173.

BBK (2020). Bundesamt für Bevölkerungsschutz und Katastrophenhilfe - Zivilschutz. https://www.bbk.bund.de/DE/ AufgabenundAusstattung/Zivilschutz/Zivischutz_node.html. Accessed 16.03.2020.

Berkemeier, L., Zobel, B., Werning, S., Ickerott, I., \& Thomas, O. (2019). Engineering of augmented reality-based information systems. Business \& Information Systems Engineering, 61(1), 67-89.

Bolstad, C. A., Riley, J. M., Jones, D. G., \& Endsley, M. R. (2012). Using goal directed task analysis with Army brigade officer teams. Proceedings of the Human Factors and Ergonomics Society Annual Meeting, 46(3), 472-476.

Bossu, R., Roussel, F., Fallou, L., Landès, M., Steed, R., Mazet-Roux, G., Dupont, A., Frobert, L., \& Petersen, L. (2018). LastQuake: From rapid information to global seismic risk reduction. International Journal of Disaster Risk Reduction, 28, 32-42.

Braly, A. M., Nuernberger, B., \& Kim, S. Y. (2019). Augmented reality improves procedural work on an international Space Station science instrument. Human Factors, 61(6), 866-878.

Brandao, W. L., \& Pinho, M. S. (2017). Using augmented reality to improve dismounted operators' situation awareness. In Paper presented at the IEEE conference on virtual reality and $3 D$ user interfaces. CA, USA.: Los Angeles.

Brunetti, P., Croatti, A., Ricci, A., \& Viroli, M. (2015). Smart augmented fields for emergency operations. Procedia Computer Science, 63, 392-399.

Buck, D. A., Trainor, J. E., \& Aguirre, B. E. (2006). A critical evaluation of the incident command system and NIMS. Journal of Homeland Security and Emergency Management, 3(3), 20-33.

Cameron, M. A., Power, R., Robinson, B., \& Yin, J. (2012). Emergency situation awareness from twitter for crisis management. Paper presented at the international conference on world wide web, Lyon, France.

Carver, L., \& Turoff, M. (2007). Human-computer interaction: The human and computer as a team in emergency management information systems. Communications of the ACM, 50(3), 33-38.

Casson, R. W. (1983). Schemata in cognitive anthropology. Annual Review of Anthropology, 12, 429-462.

Chandler, T., Cordeil, M., Czauderna, T., Dwyer, T., Glowacki, J., Goncu, C., et al. (2015). Immersive analytics. Paper presented at the international symposium on big data visual analytics. Australia: Hobart.

Crooks, A., Croitoru, A., Stefanidis, A., \& Radzikowski, J. (2013). \#Earthquake: Twitter as a distributed sensor system. Transactions in GIS, 17(1), 124-147.

Dawes, S. S., \& Cresswell, A. M. (2004). Learning from crisis: Lessons in human and information infrastructure from the world trade center response. Social Science Computer Review, 22(1), 52-66.

De Leoni, M., De Rosa, F., Marrella, A., Mecella, M., Poggi, A., Krek, A., et al. (2007). Emergency management: From user requirements to a flexible $P 2 P$ architecture. Paper presented at the International Conference on Information Systems for Crisis Response and Management, Delft, The Netherlands.

Dixon, B. J., Daly, M. J., Chan, H., Vescan, A. D., Witterick, I. J., \& Irish, J. C. (2013). Surgeons blinded by enhanced navigation: The effect of augmented reality on attention. Surgical Endoscopy, 27(2), 454 461.

Eismann, K., Posegga, O., \& Fischbach, K. (2016). Collective behaviour, social media, and disasters: A systematic literature review. Paper presented at the European Conference on Information Systems, Istanbul, Turkey.

ElSayed, N. A., Thomas, B. H., Marriot, K., Piantadosi, J., \& Smith, R. T. (2016). Situated analytics: Demonstrating immersive analytical tools with augmented reality. Journal of Visual Languages \& Computing, 36, 13-23.

Endsley, M. R. (1993). A survey of situation awareness requirements in air-to-air combat fighters. International Journal of Aviation Psychology, 3(2), 157-168.

Endsley, M. R. (1996). Automation and situation awareness. In R. Parasuraman \& M. Mouloua (Eds.), Automation and human performance: Theory and applications (pp. 163-181). Mahwah, NJ: Lawrence Erlbaum Associates, Inc..

Endsley, M. R., \& Connors, E. S. (2008). Situation awareness: State of the art. Paper presented at the IEEE Power and Energy Society General Meeting, Pittsburgh, PA, USA.

Endsley, M. R., \& Garland, D. J. (2000). Situation awareness analysis and measurement. Mahwah, NJ: Lawrence Erlbaum Associates Publishers.

Endsley, M. R., Bolté, B., \& Jones, D. G. (2003). Designing for situation awareness: An approach to user-centered design. London: Taylor $\&$ Francis.

Feng, Y. H., \& Lee, C. J. (2010). Exploring development of serviceoriented architecture for next generation emergency management system. Paper presented at the IEEE International Conference on Advanced Information Networking and Applications Workshops, Perth, Australia.

Ghosh, S., Ghosh, K., Ganguly, D., Chakraborty, T., Jones, G. J., Moens, M. F., \& Imran, M. (2018). Exploitation of social media for emergency relief and preparedness: Recent research and trends. Information Systems Frontiers, 20(5), 901-907.

Heverin, T., \& Zach, L. (2012). Use of microblogging for collective sense-making during violent crises: A study of three campus shootings. Journal of the American Society for Information Science and Technology, 63(1), 34-47.

Hiltz, S. R., \& Plotnick, L. (2013). Dealing with Information Overload When Using Social Media for Emergency Management: Emerging Solutions. Paper presented at the International Conference on Information Systems for Crisis Response and Management, Baden-Baden, Germany.

Hiltz, S. R., Hughes, A. L., Imran, M., Plotnick, L., Power, R., \& Turoff, M. (2020). Exploring the usefulness and feasibility of software requirements for social media use in emergency management. International Journal of Disaster Risk Reduction, 42.

Housel, T. J., Sawy, O. A. E., \& Donovan, P. F. (2006). Information Systems for Crisis Management: Lessons from Southern California Edison. MIS Quarterly, 10(4), 389-400.

Houston, J. B., Hawthorne, J., Perreault, M. F., Park, E. H., Hode, M. G., Halliwell, M. R., et al. (2015). Social media and disasters: A functional framework for social media use in disaster planning, response, and research. Disasters, 39(1), 1-22.

Huang, Y. L., Starbird, K., Orand, M., Stanek, S. A., \& Pedersen, H. T. (2015). Connected through crisis: Emotional proximity and the spread of misinformation online. Paper presented at the ACM conference on computer supported cooperative. Vancouver, BC, Canada: Work \& Social Computing. 
Humphrey, C. M. (2009). Information abstraction visualization for human-robot interaction. Doctoral dissertation, Vanderbilt University, Nashville

Imran, M., Elbassuoni, S., Castillo, C., Diaz, F., \& Meier, P. (2013). Extracting information nuggets from disaster-related messages in social media. Paper presented at the international conference on information Systems for Crisis Response and Management. Germany: Baden-Baden.

Imran, M., Castillo, C., Diaz, F., \& Vieweg, S. (2015). Processing social media messages in mass emergency: A survey. ACM Computing Surveys, 47(4), 1-38.

Jenkins, M. P., \& Young, D. (2016). BARRACUDA: An augmented reality display for increased motorcyclist en route hazard awareness. Paper presented at the IEEE international multi-disciplinary conference on cognitive methods in situation awareness and decision support. CA, USA: San Diego.

Jones, R. E. T., Cuevas, H. M., Bolstad, C., Anderson, T. J., Horn, D., \& Endsley, M. R. (2010). Disaster Management Systems. In T. L. Smith-Jackson, M. L. Resnick, \& K. T. Johnson (Eds.), Cultural ergonomics: Theory, methods, and applications (pp. 169-184). Boca Raton, FL: CRC Press.

Jones, D. G., Endsley, M. R., Bolstad, M., \& Estes, G. (2012). The Designer's situation awareness toolkit: Support for user-centered design. Proceedings of the Human Factors and Ergonomics Society Annual Meeting, 48(3), 653-657.

Kaplan, A. M., \& Haenlein, M. (2010). Users of the world, unite! The challenges and opportunities of social media. Business Horizons, 53(1), 59-68.

Kuckartz, U., Dresing, T., Rädiker, S., \& Stefer, C. (2008). Qualitative Evaluation: Der Einstieg in die Praxis. Wiesbaden: VS Verlag für Sozialwissenschaften.

Landwehr, P. M., \& Carley, K. M. (2014). Social media in disaster relief. In W. W. Chu (Ed.), Data mining and knowledge discovery for big data. Methodologies, challenge and opportunities (Vol. 1, pp. 225 257). Berlin: Springer.

Lazreg, M. B., Chakraborty, N. R., Stieglitz, S., Potthoff, T., Ross, B., \& Majchrzak, T. A. (2018). Social media analysis in crisis situations: Can social media be a reliable information source for emergency management services? Paper presented at the International Conference on Information Systems Development, Lund, Sweden.

Li, C., Weng, J., He, Q., Yao, Y., Datta, A., Sun, A., et al. (2012). TwiNER: Named entity recognition in targeted twitter stream. Paper presented at the International ACM SIGIR Conference on Research and Development in Information Retrieval, Portland, OR, USA.

Li, X., Caragea, D., Caragea, C., Imran, M., \& Ofli, F. (2019). Identifying disaster damage images using a domain adaptation approach. Paper presented at the international conference on information Systems for Crisis Response and Management. Spain: València.

Lindemann, P., Lee, T. Y., \& Rigoll, G. (2019). Supporting Driver Situation Awareness for Autonomous Urban Driving with an Augmented-Reality Windshield Display. Paper presented at the IEEE International Symposium on Mixed and Augmented Reality. Germany: Munich.

Luchetti, G., Mancini, A., Sturari, M., Frontoni, E., \& Zingaretti, P. (2017). Whistland: An augmented reality crowd-mapping system for civil protection and emergency management. International Journal of Geo-Information, 6(2), 41.

Ludwig, T., Reuter, C., \& Pipek, V. (2015a). Social haystack: Dynamic quality assessment of citizen-generated content during emergencies. ACM Transactions on Computer-Human Interaction, 22(4), 1-27.

Ludwig, T., Reuter, C., Siebigteroth, T., \& Pipek, V. (2015b). CrowdMonitor: Mobile crowd sensing for assessing physical and digital activities of citizens during emergencies. Paper presented at the Annual ACM Conference on Human Factors in Computing Systems. South Korea: Seoul.
Luna, S., \& Pennock, M. J. (2018). Social media applications and emergency management: A literature review and research agenda. International Journal of Disaster Risk Reduction, 28, 565-577.

Mayring, P. (2014). Qualitative content analysis: Theoretical foundation, basic procedures and software solution (Erstveröffentlichung ed.). Klagenfurt: Beltz.

McLean, H. (2015). Social media benefits and risks in earthquake events. In M. Beer, I. A. Kougioumtzoglou, E. Patelli, \& S.-K. Au (Eds.), Encyclopedia of earthquake engineering (Vol. 54, pp. 3309-3315). Berlin: Springer.

Mignone, A. T., \& Davidson, R. (2003). Public health response actions and the use of emergency operations centers. Prehospital and Disaster Medicine, 18(3), 217-218.

Milgram, P., \& Kishino, F. (1994). A taxonomy of mixed reality visual displays. Transactions on Information Systems, 77(12), 1321-1329.

Militello, L. G., Patterson, E. S., Bowman, L., \& Wears, R. (2007). Information flow during crisis management: Challenges to coordination in the emergency operations center. Cognition, Technology and Work, 9, 25-31.

Mirbabaie, M., \& Zapatka, E. (2017). Sensemaking in social media crisis communication - A case study on the Brussels bombings in 2016. Paper presented at the European conference on information systems, Guimarães, Portugal.

Nunes, I. L., Lucas, R., Mário, S.-M., \& Correia, N. (2019). An augmented reality application to support deployed emergency teams. In S. Bagnara, R. Tartaglia, S. Albolino, T. Alexander, \& Y. Fujita (Eds.), Proceedings of congress of the international ergonomics association (Vol. 822, pp. 195-204). Cham: Springer.

Olshannikova, E., Ometov, A., Koucheryavy, Y., \& Olsson, T. (2015). Visualizing big data with augmented and virtual reality: Challenges and research agenda. Journal of Big Data, 2(1), 22.

Olteanu, A., Vieweg, S., \& Castillo, C. (2015). What to expect when the unexpected happens: Social media communications across crises. Paper presented at the ACM Conference on Computer Supported Cooperative Work \& Social Computing, Vancouver, BC, Canada.

Palen, L., \& Vieweg, S. (2008). The emergence of online widescale interaction in unexpected events: Assistance, alliance \& retreat. Paper presented at the ACM Conference on Computer Supported Cooperative Work. CA, USA: San Diego.

Palen, L., Vieweg, S., Liu, S. B., \& Hughes, A. L. (2009). Crisis in a networked world: Features of computer-mediated communication in the April 16, 2007, Virginia Tech event. Social Science Computer Review, 27(4), 467-480.

Palen, L., Vieweg, S., \& Anderson, K. M. (2011). Supporting "everyday analysts" in safety- and time-critical situations. The Information Society, 27(1), 52-62.

Palmarini, R., Erkoyuncu, J. A., Roy, R., \& Torabmostaedi, H. (2018). A systematic review of augmented reality applications in maintenance. Robotics and Computer-Integrated Manufacturing, 49, 215-228.

Park, B. J., Yoon, C., Lee, J. W., \& Kim, K. H. (2015). Augmented reality based on driving situation awareness in vehicle. Paper presented at the International Conference on Advanced Communication Technology. South Korea: Seoul.

Paulusová, J., \& Paulus, M. (2018). Situational awareness in HMI of industrial plants. Paper presented at the International Carpathian Control Conference. Hungary: Szilvasvarad.

Perry, R. W. (2003). Emergency operations centres in an era of terrorism: Policy and management functions. Journal of Contingencies and Crisis Management, 11(4), 151-159.

Pfaff, M. S. (2015). Identifying option awareness requirements for public health crisis decision making. Proceedings of the Human Factors and Ergonomics Society Annual Meeting, 59(1), 548-552.

Plotnick, L., \& Hiltz, S. R. (2016). Barriers to use of social media by emergency managers. Journal of Homeland Security and Emergency Management, 13(2), 247-277. 
Reuter, C., Ludwig, T., Friberg, T., Pratzler-Wanczura, S., \& Gizikis, A. (2015). Social media and emergency services?: Interview study on current and potential use in 7 European countries. International Journal of Information Systems for Crisis Response and Management, 7(2), 36-58.

Rosenthal, U., \& Hart, P. t. (1991). Experts and decision makers in crisis situations. Science Communication, 12, 350-372.

Rosenthal, U., Boin, A., \& Comfort, L. K. (2001). Managing crises: Threats, dilemmas, opportunities. Springfield, IL: Charles C Thomas.

Rowen, A., Grabowski, M., Rancy, J., \& Crane, A. (2019). Impacts of wearable augmented reality displays on operator performance, situation awareness, and communication in safety-critical systems. Applied Ergonomics, 80, 17-27.

Rummukainen, L., Oksama, L., Timonen, J., \& Vankka, J. (2015). Situation awareness requirements for a critical infrastructure monitoring operator. Paper presented at the IEEE international symposium on Technologies for Homeland Security. Waltham: MA, USA.

Salvendy, G. (2012). Handbook of Human Factors and Ergonomics (4ed.). Hoboken, NJ: Wiley.

Sarter, N., \& Woods, D. (1991). Situation awareness: A critical but illdefined phenomenon. International Journal of Aviation Psychology, l(1), 45-57.

Seppänen, H., Mäkelä, J., Luokkala, P., \& Virrantaus, K. (2013). Developing shared situational awareness for emergency management. Safety Science, 55, 1-9.

Stanton, N., Chambers, P., \& Piggott, J. (2001). Situational awareness and safety. Safety Science, 39, 189-204.

Starbird, K., \& Palen, L. (2010). Pass it on?: Retweeting in mass emergency. Paper presented at the international conference on information Systems for Crisis Response and Management. WA, USA: Seattle.

Starbird, K., Muzny, G., \& Palen, L. (2012). Learning from the crowd: Collaborative filtering techniques for identifying on-the-ground Twitterers during mass disruptions. Paper presented at the International Conference on Information Systems for Crisis Response and Management. Canada: Vancouver.

Steffen, J. H., Gaskin, J., Meservy, T., \& Jenkins, J. (2017). The missing framework for virtually assisted activities. Paper presented at the international conference on information systems. South Korea: Seoul.

Stieglitz, S., Mirbabaie, M., Schwenner, L., Marx, J., Lehr, J., \& Brünker, F. (2017). Sensemaking and communication roles in social media crisis communication. Paper presented at the International Conference on Wirtschaftsinformatik. Switzerland: St. Gallen.

Stieglitz, S., Bunker, D., Mirbabaie, M., \& Ehnis, C. (2018a). Sensemaking in social media during extreme events. Journal of Contingencies and Crisis Management, 26(1), 4-15.

Stieglitz, S., Meske, C., Ross, B., \& Mirbabaie, M. (2018b). Going back in time to predict the future-the complex role of the data collection period in social media analytics. Information Systems Frontiers, 22, $1-15$.

Stieglitz, S., Mirbabaie, M., Fromm, J., \& Melzer, S. (2018c). The adoption of social media analytics for crisis management - challenges and opportunities. Portsmouth, UK: Paper presented at the European Conference on Information Systems.

Stieglitz, S., Mirbabaie, M., \& Milde, M. (2018d). Social positions and collective sense-making in crisis communication. International Journal of Human-Computer Interaction, 34(4), 328-355.

Stieglitz, S., Mirbabaie, M., Ross, B., \& Neuberger, C. (2018e). Social media analytics - Challenges in topic discovery, data collection, and data preparation. International Journal of Information Management, 39, 156-168

Sutton, J., Palen, L., \& Shklovsk, I. (2008). Backchannels on the front lines: Emergent uses of social media in the 2007 Southern California wildfires. Paper presented at the International
Conference on information Systems for Crisis Response and Management. DC, USA: Washington.

Tapia, A. H., Moore, K. A., \& Johnson, N. J. (2013). Beyond the trustworthy tweet: A deeper understanding of microblogged data use by disaster response and humanitarian relieforganizations. Paper presented at the International Conference on Information Systems for Crisis Response and Management. Germany: Baden-Baden.

Taylor, T. B. (2004). Information management in the emergency department. Emergency Medicine Clinics of North America, 22(1), 241257.

Troudi, A., Zayani, C. A., Jamoussi, S., \& Amor, I. A. B. (2018). A new mashup based method for event detection from social media. Information Systems Frontiers, 20(5), 981-992.

Usher, J. M., \& Kaber, D. B. (2000). Establishing information requirements for supervisory controllers in a flexible manufacturing system using GTA. Human Factors and Ergonomics in Manufacturing, 10, 431-452.

Valecha, R. (2019). An investigation of interaction patterns in emergency management: A case study of the crash of continental flight 3407. Information Systems Frontiers.

Van Krevelen, D. W. F., \& Poelman, R. (2010). A survey of augmented reality technologies, applications and limitations. International Journal of Virtual Reality, 9(2), 1-21.

Verma, S., Vieweg, S., Corvey, W. J., Palen, L., Martin, J. H., Palmer, M., et al. (2011). K.M.: Natural language processing to the rescue?: Extracting 'situational awareness' tweets during mass emergency. Paper presented at the International AAAI Conference on Web and Social Media, Barcelona, Spain.

Waz (2019). Sturm Eberhard: Ein Toter und mindestens 27 Verletzte in NRW. https://www.waz.de/region/rhein-und-ruhr/sturm-eberhardein-toter-und-mindestens-27-verletzte-in-nrw-id216625297.html. Accessed 27.03.2020.

Young, J. C., Wald, D., Earle, P., \& Shanley, L. (2013). Transforming earthquake detection and science through citizen seismology. Washington, DC: Woodrow Wilson International Centre for Scholars.

Zade, H., Shah, K., Rangarajan, V., Kshirsagar, P., Imran, M., \& Starbird, K. (2018). From situational awareness to actionability: Towards improving the utility of social media data for crisis response. Proceedings of the ACM on Human-Computer Interaction, 2, 1-18.

Zahra, K., Imran, M., \& Ostermann, F. O. (2020). Automatic identification of eyewitness messages on twitter during disasters. Information Processing and Management, 57(1), 102107.

Publisher's Note Springer Nature remains neutral with regard to jurisdictional claims in published maps and institutional affiliations.

Jennifer Fromm is a $\mathrm{PhD}$ candidate at the Department of Computer Science and Applied Cognitive Science at the University of DuisburgEssen, Germany. She received a master's degree in Applied Cognitive and Media Science from the University of Duisburg-Essen, Germany. Her studies focus on the effective use of virtual and augmented reality in meaningful application areas such as crisis management and higher education. Her research has been presented, for example, at the European Conference on Information Systems, the Australasian Conference on Information Systems, and the International Conference on Wirtschaftsinformatik. Her research has been published in journals such as Computers \& Education and the International Journal of Information Systems for Crisis Response and Management.

Kaan Eyilmez holds a Bachelor's degree in Applied Cognitive and Media Science and graduated from University of Duisburg-Essen, Germany. He is interested in crisis communication and the usage of augmented and virtual reality. 
Melina Baßfeld holds a Bachelor's degree in Applied Cognitive and Media Science and graduated from University of Duisburg-Essen, Germany. She is interested in usability engineering and web design of social media monitoring tools.

Tim A. Majchrzak is professor in Information Systems at the University of Agder (UiA) in Kristiansand, Norway. He also is a member of the Centre for Integrated Emergency Management (CIEM) at UiA. His research comprises both technical and organizational aspects of Software Engineering, often in the context of Mobile Computing. He has also published work on diverse interdisciplinary Information Systems topics, most notably targeting Crisis Prevention and Management. Tim's research projects typically have an interface to industry and society. He is a senior member of the IEEE and the IEEE Computer Society, and a member of the Gesellschaft für Informatik e.V.
Stefan Stieglitz is a professor and head of the research group for Professional Communication in Electronic Media/Social Media at the University of Duisburg-Essen, Germany. In his research, he investigates how to make use of social media data. Moreover, he analyzes user behavior and technology adoption of collaborative informationsystems in organizational contexts. He is director and founder of the Competence Center Connected Organization. Stefan has been an honorary professor at University of Sydney since 2018. His work has been published in reputable journals such as the Journal of Management Information System (JMIS), European Journal of InformationSystems (EJIS), Journal of Information Technology (JIT) and Business \& Information Systems Engineering (BISE). In 2016, one of his articles was recognized with the 'AIS Senior Scholars Best IS Publications Award'. 